NBER WORKING PAPER SERIES

WHO WILL PAY FOR LEGACY UTILITY COSTS?

Lucas W. Davis

Catherine Hausman

Working Paper 28955

http://www.nber.org/papers/w28955

\author{
NATIONAL BUREAU OF ECONOMIC RESEARCH \\ 1050 Massachusetts Avenue \\ Cambridge, MA 02138 \\ June 2021, Revised March 2022
}

We have not received any financial compensation for this project, nor do we have any financial relationships that relate to this research. We thank Marshall Blundell for excellent assistance with the utility service territory data. We are thankful to Severin Borenstein, Eva Lyubich, Justin Kirkpatrick, William Wheeler, and seminar and conference participants at the University of Illinois, Midwest Energy Fest, WEAI, UC Berkeley, University of Hawaii, Environmental Protection Agency, Resources for the Future, and Indiana University for helpful comments. The views expressed herein are those of the authors and do not necessarily reflect the views of the National Bureau of Economic Research.

NBER working papers are circulated for discussion and comment purposes. They have not been peer-reviewed or been subject to the review by the NBER Board of Directors that accompanies official NBER publications.

(C) 2021 by Lucas W. Davis and Catherine Hausman. All rights reserved. Short sections of text, not to exceed two paragraphs, may be quoted without explicit permission provided that full credit, including $\odot$ notice, is given to the source. 
Who Will Pay for Legacy Utility Costs?

Lucas W. Davis and Catherine Hausman

NBER Working Paper No. 28955

June 2021, Revised March 2022

JEL No. L95,L97,Q40,Q48,R11

\begin{abstract}
The growing "electrify everything" movement aims to reduce carbon dioxide emissions by transitioning households and firms away from natural gas toward electricity. This paper considers what this transition means for the customers who are left behind. Using historical evidence from growing and shrinking U.S. natural gas utilities, we show that utilities add pipelines but rarely remove them, even when the customer base from which to recover costs is shrinking. Correspondingly, we find that utility revenues decrease less than one-for-one when a customer base is shrinking, consistent with higher bills for remaining customers. We then use our empirical estimates to predict how customer bills might increase in the future for different levels of building electrification. We highlight the equity implications of our results and conclude by discussing alternative utility financing options such as recouping fixed costs through taxes rather than prices.
\end{abstract}

\author{
Lucas W. Davis \\ Haas School of Business \\ University of California \\ Berkeley, CA 94720-1900 \\ Berkeley, CA 94720-1900 \\ and NBER \\ ldavis@haas.berkeley.edu \\ Catherine Hausman \\ Gerald R. Ford School of Public Policy \\ University of Michigan \\ 735 South State Street \\ Ann Arbor, MI 48109 \\ and NBER \\ chausman@umich.edu
}




\title{
Who Will Pay for Legacy Utility Costs?
}

\author{
Lucas W. Davis Catherine Hausman*
}

\begin{abstract}
The growing "electrify everything" movement aims to reduce carbon dioxide emissions by transitioning households and firms away from natural gas toward electricity. This paper considers what this transition means for the customers who are left behind. Using historical evidence from growing and shrinking U.S. natural gas utilities, we show that utilities add pipelines but rarely remove them, even when the customer base from which to recover costs is shrinking. Correspondingly, we find that utility revenues decrease less than one-for-one when a customer base is shrinking, consistent with higher bills for remaining customers. We then use our empirical estimates to predict how customer bills might increase in the future for different levels of building electrification. We highlight the equity implications of our results and conclude by discussing alternative utility financing options such as recouping fixed costs through taxes rather than prices.
\end{abstract}

Keywords: natural monopoly, stranded costs, sunk costs, natural gas, energy utilities, building electrification, inequality, energy transition, energy justice

JEL Codes: L95, Q40, R11, L97, Q48

*(Davis) University of California, Berkeley. Email: lwdavis@berkeley.edu. (Hausman) University of Michigan. Email: chausman@umich.edu. We have not received any financial compensation for this project, nor do we have any financial relationships that relate to this research. We thank Marshall Blundell for excellent assistance with the utility service territory data. We are thankful to Severin Borenstein, Eva Lyubich, Justin Kirkpatrick, William Wheeler, and seminar and conference participants at the University of Illinois, Midwest Energy Fest, WEAI, UC Berkeley, University of Hawaii, Environmental Protection Agency, Resources for the Future, and Indiana University for helpful comments. 


\section{Introduction}

Natural monopolies typically recover fixed costs by spreading fees out over their customer base across time, whether through per-unit fees, per-customer fees, or a combination. In the U.S., this is true of privately-held utilities, municipally-run utilities, and utilities run by other governmental agencies (e.g., federal) across a broad range of goods: electricity, natural gas, water, wastewater services, garbage collection, and more. Seldom discussed in the literature is that in times of a shrinking customer base, this approach can lead to difficulties recovering fixed costs; either prices must rise, or costs (such as maintenance of infrastructure) must be cut.

This dynamic is important for understanding the effects of environmental policies that target utilities. In particular, this issue is currently coming to a head with U.S. natural gas utilities due to a growing number of policies aimed at transitioning customers away from natural gas towards electricity. ${ }^{1}$ Building electrification has been called "a linchpin solution for decarbonization" (National Academies of Sciences, Engineering, and Medicine, 2021), and recent proposals for a transition to carbon neutrality rely on scenarios in which the vast majority of the building stock is transitioned to all-electric in a few decades (Larson et al., 2020; National Academies of Sciences, Engineering, and Medicine, 2021; Williams et al., 2021).

This paper considers what such a transition would look like for the natural gas customers who are left behind. The current push for building electrification is still in its early stages, so it is too soon for an empirical analysis of how utility behavior responds to this policy push. Instead, we use historical evidence from growing and shrinking utilities. Although mostly driven by reasons other than building electrification, this evidence is nonetheless a valuable opportunity to learn how utilities change their operations and finances when large numbers of customers enter or exit.

First, we demonstrate that both customer base growth and customer base loss are commonplace among U.S. natural gas distribution utilities during our sample period of 1997-2019. We observe, for example, 320 utilities that experienced five or more consecutive years of customer growth, and 250 utilities that experienced five or more consecutive years of customer base decline. Although the total number of natural gas customers in the U.S. has increased 25 percent over this time period, many specific regions have lost population, and we show

\footnotetext{
${ }^{1} \mathrm{~A}$ number of policies have been introduced to encourage electrification, including municipal bans on natural gas in new construction, electric preferred building codes, and subsidies for heat pumps. These policies are in part motivated by the ongoing decline in emissions from the electricity sector (Holland et al., 2020), which means that transitioning households and firms from natural gas to electricity could significantly reduce environmental damages.
} 
that customer base declines are associated with net migration patterns. For example, Alabama Gas Corp - a large utility serving Birmingham and much of central Alabama - has consistently experienced a shrinking customer base at the same time the city of Birmingham has lost population.

Second, we examine what these customer base changes mean for utility operations. For most natural gas distribution utilities, the pipeline infrastructure is the single largest asset and the single largest fixed cost. We compile annual data on the total number of pipeline miles operated by each utility, and test how this responds to changes in the customer base. We find that when utilities are growing, they add pipelines. A ten percent increase in the number of residential customers leads to a four percent increase in the length of the distribution network. However, when utilities are shrinking, they do not remove pipelines. A ten percent decrease in the number of residential customers has a precisely estimated zero percent effect on the length of the distribution network. Utilities add pipelines but rarely remove them, even when the customer base from which to recover costs is shrinking. ${ }^{2}$

Third, we test for changes in utility finances. As with pipelines, we find that utility revenues respond asymmetrically to changes in the customer base. New customers lead to one-to-one revenue increases, with a ten percent increase in residential customers increasing revenues by ten percent. In contrast, customer losses lead to a less than one-to-one decrease in revenue, with a ten percent decrease in residential customers decreasing revenues by only about five percent. This pattern implies that remaining customers make up about half of the lost revenue through increased prices. The remaining half may represent cost savings, or it may represent losses to shareholders, an issue we discuss. While previous white papers have pointed to the possibility of bill impacts, we provide the first empirical evidence on the magnitude of these effects using comprehensive data and a quasi-experimental strategy.

These increased bills for remaining customers have significant equity implications. We show that many shrinking utilities in our data serve cities with high rates of poverty and with large African-American populations; in parts of the Rust Belt and Appalachia; and in some rural areas. Looking forward, the current push for building electrification is likely to lead to a very different pattern of customer exit. Nonetheless, in both cases there is a set of remaining customers left facing higher bills, and our results underscore the potential for these impacts to be highly uneven across income levels and racial groups.

We use our empirical estimates to predict how customer bills might increase in the future for different levels of building electrification, absent regulatory changes. We find that bill

\footnotetext{
${ }^{2} \mathrm{~A}$ similar asymmetry arises with "durable housing" and the idea that it is relatively easy to build more homes as demand increases, but that those homes remain even after demand decreases (Glaeser and Gyourko, 2005).
} 
impacts are modest as small numbers of households transition away from natural gas: for a 20 percent reduction in residential gas customers, we calculate bill increases of around $\$ 40$ per year for remaining customers. However, impacts increase non-linearly as an increasing number of households leaves natural gas. For a 40 percent reduction in customers, we calculate bill increases of $\$ 115$ per year.

To understand how customer exit could lead to these outcomes, we next examine ancillary data on categories of expenditures for a sample of large U.S. natural gas utilities. We show that a substantial portion of expenditures are fixed costs that, at least in the short run, are unlikely to change as customers leave natural gas service. This includes capital costs (25\%), maintenance and operations (10\%), and administrative expenses such as pension payments $(10 \%)$.

Finally, we discuss various alternatives for financing legacy costs. While the norm has been to pay for these costs through monthly bills, we explore, for example, the possibility of collecting hook-up and exit fees. We also raise the possibility of shifting costs to utility shareholders, across utilities, or to the general tax base. With each alternative we briefly discuss the likely impacts for remaining customers as well as the broader implications for efficiency and equity.

Several features of the natural gas market make it a particularly good setting for such an analysis. First, natural gas distribution is a quintessential natural monopoly, making it an ideal setting for studying what happens to legacy utility costs during market transitions. Second, even relative to other utilities like electricity distribution companies, both the physical pipeline infrastructure and financial data such as revenue are particularly well observed, a product of the highly regulated nature of the industry. We note that the industry is regulated in part precisely because it is a natural monopoly, but also because proper maintenance of the distribution network is important for safety and environmental reasons - inadequate maintenance can lead to pipeline explosions and to methane leaks. Finally, natural gas has historically provided important services (heating, cooking, and water heating) to a large portion of U.S. households and firms. As of 2019, natural gas was used in the U.S. by 70 million households and 6 million commercial establishments, and sales in these two sectors totaled $\$ 70$ billion.

Our paper contributes to a broader literature on infrastructure investment, fixed cost recovery, and the optimal regulation of natural monopolies. This literature has emphasized a number of regulatory challenges in this environment, including how to create incentivecompatible regulations that allow for cost-minimization without sacrificing infrastructure quality or other goals (Bonbright, 1941; Averch and Johnson, 1962; Viscusi, Vernon and Harrington, 2005; McRae, 2015). We consider a previously understudied dynamic issue: 
customer base loss and the recovery of legacy infrastructure costs. While we focus on natural gas in our empirical example, the mechanisms we document are likely to apply to other natural monopolies that recover fixed costs by spreading fees across customers, including water utilities; urban transit; the transition from landlines to wireless; the impact of rooftop solar on electricity distribution; etc. ${ }^{3}$

Our paper also contributes to a broader literature on natural gas utilities. Natural gas combustion currently makes up around one third of total US fossil-fuel related CO2 emissions (Environmental Protection Agency, 2021), and papers exploring how the natural gas sector contributes to climate change include Newell and Raimi (2013), Hausman and Kellogg (2015), Mason, Muehlenbachs and Olmstead (2015), and Marks (2022). Focusing on distribution utilities, Hausman and Muehlenbachs (2019) look at regulatory impacts on the incentives for environmental and safety protection. Natural gas rate design has been explored by Knittel (2003); Davis and Muehlegger (2010); Borenstein and Davis (2012); Auffhammer and Rubin (2021); and Hausman (2019). Perhaps most closely related is the work on bypass, which examines industrial customer retention (Laffont and Tirole, 1990), for instance at the time of deregulation of wholesale natural gas prices. ${ }^{4}$

Our paper speaks directly to policy issues around building electrification. Davis (2021) empirically examines the customer decision-making around home heating technologies, calculating willingness to pay to avoid an all-electric transition. A number of white papers have examined costs and benefits of building electrification in California (Bilich, Colvin and O'Connor, 2019; Greenlining Institute, 2019; Gridworks, 2019; Mahone et al., 2019; Aas et al., 2020). But we are not aware of any statistical analysis applying to the broader United States.

Our work also speaks to questions of the incidence of environmental policies, an issue explored at depth in Bento (2013) and Fullerton and Muehlegger (2019). In particular, our analysis is related to a recent and growing literature on equity issues in energy transitions. This is crucial for analyzing climate policies, including how to best structure them and who

\footnotetext{
${ }^{3}$ Cost recovery difficulties associated with customer base changes have been pointed out for water utilities (Beecher, Mann and Landers, 1990; Beecher, Dreese and Landers, 1992; Faust, Abraham and McElmurry, 2016; Beecher, 2020; Swain, McKinney and Susskind, 2020); and (Galster, 2017) makes this connection for population loss and the provision of city services. Gabel and Burns (2012) similarly discuss cost recovery issues in the transition from landlines to wireless and voice-over internet.

${ }^{4}$ Relatedly, studies of electricity market deregulation have emphasized the crucial role played by stranded costs, i.e. utility investments which would be unrecoverable in a deregulated market. White (1996) argues that, "this stranded cost problem is by far the most controversial aspect of regulatory reform in the electric power industry." Borenstein and Bushnell (2015) argue that U.S. electricity market deregulation was motivated largely by "an opportunity to shift responsibility for paying the sunk costs of what were considered uneconomic stranded assets." Although the catalyst is quite different (deregulation versus energy transition), the economics of these fixed, mostly sunk costs is similar to the legacy costs that would be borne in a transition away from natural gas.
} 
will be the winners and losers of the policies. For instance, Van der Ploeg and Rezai (2020) discusses how an unanticipated transition could result in billions of dollars in stranded assets in fossil fuel industries.

Most closely related in this vein is the work examining how rooftop solar can push fixed cost recovery onto low-income customers (Burger, 2019; Borenstein, Fowlie and Sallee, 2021)

- this is a function of high mark-ups in high-solar penetration areas like California. In contrast, the mechanism in our paper is a function of customer losses, which applies even when fixed costs are recovered through fixed fees. Thus the standard rate reforms that are frequently suggested for rooftop solar would still lead to fixed cost recovery issues and equity challenges in our setting. A similar mechanism could apply to the electricity sector in future scenarios with so-called "grid defection," in which the installation of storage along with the rooftop solar allows a customer to disconnect from an electric utility altogether (Gorman, Jarvis and Callaway, 2020). More broadly, the equity issues we document may interact with pre-existing equity issues in residential energy markets (Reames, 2016; Carley and Konisky, 2020; Lyubich, 2020).

Finally, our results on economic and racial inequities also contribute to the literature on rural depopulation (Johnson and Lichter, 2019) and on shrinking cities (Beauregard, 2009), where a combination of economic forces and racial antagonism have been identified (Boustan, 2010; Galster, 2017). We empirically show that these broad migration patterns in the United States can directly impact the ability of utilities to provide the basic services that households require. While we focus on natural gas, similar mechanisms are expected in water and other utility services.

\section{Data}

\subsection{Data Sources}

Our empirical analysis takes advantage of the unusually rich data available for the U.S. natural gas distribution sector. The highly regulated nature of this sector means that detailed information is available from multiple government agencies, including the Department of Energy and the Department of Transportation. We are able to observe key aspects relating to both physical infrastructure and to the utilities' financials, including sales, revenues, and prices.

Our core dataset is an annual panel describing essentially the universe of U.S. natural gas distribution utilities for the years 1997 to 2019. Most of this information comes from an annual census of natural gas distribution utilities conducted by the U.S. Department of 
Energy's Energy Information Administration (EIA).

This EIA-176 dataset reports customer count, volume sold, and revenue collected by end-user sector (e.g. residential versus commercial). ${ }^{5}$ These data also report the utility's ownership structure (investor-owned, municipal, etc.). ${ }^{6}$ For utilities that operate across multiple states, there is a separate entry for each state's operations. From EIA, we also observe average citygate prices at the state level, i.e. the average price (in dollars per mcf) paid by utilities in that state when purchasing natural gas. We deflate all revenue and prices by the annual consumer price index from FRED, reporting all dollar amounts in 2019 dollars.

One of our primary outcome variables is "net revenue," which we calculate by taking total utility revenue and subtracting off the portion of revenue that is collected to pay for purchasing natural gas. These additional revenues are collected to pay for pipeline investments, maintenance and operations, administrative salaries, and other costs. Whereas natural gas purchases can be easily adjusted upward and downward in response to changes in customer counts and fluctuating consumption levels, this net revenue stream is how the utility pays for fixed costs. Focusing on net revenue means that throughout the analysis we are able to largely ignore variation in natural gas commodity prices, weather, macroeconomic shocks, and other factors that lead to short-run fluctuations in utility total revenue.

Our other key data source is an annual utility-level census (1997 to 2019) from the Pipeline and Hazardous Materials Safety Administration (PHMSA) at the Department of Transportation. Natural gas distribution utilities are required under federal law to submit annual reports to PHMSA. This information is used by PHMSA and other government agencies to enforce pipeline safety regulations, track and investigate incidents, and plan inspections. Utilities are required to submit separate reports for each state in which they operate.

The primary variable we use from this dataset is the total "distribution main mileage" per utility per year. Distribution mains are the pipelines that carry natural gas under city streets. To merge the EIA and PHMSA data, we use a fuzzy string match on utility names and an exact match on the state within which the utility operates. We are able to match 83 percent of the EIA observations to PHMSA data (representing 87 percent of residential customers). See the Appendix for details.

Finally, we collect weather data from NOAA, specifically annual heating and cooling

\footnotetext{
${ }^{5}$ Our analysis throughout ignores industrial customers, as they make up a very small fraction of total customers, and because there is too little change in the number of industrial customers to support an empirical analysis.

${ }^{6}$ We simplify the designations somewhat by combining some categories. For instance, we combine "investor-owned utilities" and "privately-owned utilities," regardless of whether they are, for instance, publicly traded. We also group into the "municipal" category some rural cooperatives and a few other kinds of government-run agencies such as county-run utilities. See the Appendix for details.
} 
Table 1: Summary Statistics

\begin{tabular}{lrrrrrr}
\hline \hline & & & & & & \\
& & Mean & Median & SD & Min & Max \\
\hline Residential: & & & & & & \\
$\quad$ Customers, '000s & & & & & \\
$\quad$ Bundled customers, proportion & 29,392 & 41.31 & 1.07 & 229.60 & 0.00 & 5607.69 \\
$\quad$ Dummy, customer base growing & 27,671 & 1.00 & 1.00 & 0.01 & 0.90 & 1.00 \\
$\quad$ Sales, Bcf & 29,388 & 2.51 & 1.00 & 0.50 & 0.00 & 1.00 \\
$\quad$ Average price, \$/mcf & 29,382 & 13.56 & 12.95 & 5.41 & 0.58 & 445.40 \\
$\quad$ Revenue, '000,000s & 28,977 & 27.54 & 0.72 & 129.95 & 0.00 & 3515.88 \\
$\quad$ Net revenue, '000,000s & 28,644 & 17.44 & 0.37 & 86.02 & 0.00 & 2101.42 \\
$\quad$ Per customer, '000s & 28,630 & 0.37 & 0.35 & 0.19 & 0.00 & 3.40 \\
$\quad$ Per mcf & 28,641 & 6.99 & 6.27 & 4.02 & 0.00 & 52.48 \\
Citygate price, \$/mcf & 29,392 & 6.77 & 6.13 & 2.53 & 2.03 & 36.07 \\
Miles of pipeline, '000s & 24,452 & 0.77 & 0.06 & 3.07 & 0.00 & 51.25 \\
$=1$ if investor-owned utility & 29,392 & 0.24 & 0.00 & 0.43 & 0.00 & 1.00 \\
=1 if municipal utility & 29,392 & 0.76 & 1.00 & 0.43 & 0.00 & 1.00 \\
& & & & & & \\
\hline
\end{tabular}

Note: This table provides summary statistics for our main estimation sample, an unbalanced panel covering the period 1997-2019, with approximately 1,300 natural gas distribution utilities per year. The sample excludes a small number of utilities for which more than ten percent of customers buy natural gas from a retail choice provider. There are fewer observations for the "Dummy, customer base growing" variable because it cannot be calculated for the first year a utility appears in the sample. There are fewer observations for the "Miles of pipeline" variable because of imperfect matches across data sources. Commercial customer summary statistics are in the Appendix.

degree days at the state level.

\subsection{Summary Statistics}

Table 1 provides summary statistics. Our sample consists of an unbalanced panel with around 1,300 utilities per year. Of these, around one-quarter are investor-owned utilities and three-quarters municipal utilities. The summary statistics reveal the tremendous variation in utility size, including substantial skew. The mean number of residential customers is 41,000 , but the median number is 1,000 . This skewness reflects the fact that there are many small municipally-operated natural gas utilities, as well as a much smaller number of large investor-owned utilities like Southern California Gas Company, which serves nearly six million households.

Our main specification limits the sample in a few ways to reduce measurement error. First, we focus on utilities for which at least 90 percent of residential customers are "bundled," rather than "retail choice." Fewer than two percent of utilities are dropped because of this exclusion. Second, we assign new utility identification numbers when we observe an annual residential customer change of more than 20 log points or a commercial change of more than $50 \log$ points. These large changes likely indicate service territory adjustments, mergers, or acquisitions rather than true customer growth or loss. In specifications using differences, this assignment of a new identification number drops the year with the large 
change but keeps subsequent years. Third, we drop a small number of extreme outliers for the other variables, which we attribute to clerical errors and other reporting mistakes. See the Appendix for details.

Finally, in our regression analysis we focus on utility-years that are part of at least a two-year period of sustained growth or loss. That is, we drop observations where a utility grows in one year, shrinks in the next, etc. We do this for two reasons. First, for our thought experiment of a utility losing customers because of electrification, we are interested in sustained patterns of loss. Second, if the miles and customer counts are measured at different times in a year, the year-on-year changes may not match up in time. This would be most concerning if a utility grows in one part of a year but shrinks in another part of the year. In the Appendix, we show results relaxing this and each of the other sample selection criteria.

\section{Growing and Shrinking Utilities}

We are interested in how utility operations and infrastructure investments respond to changes in the size of the customer base. Of course, historical evidence of these patterns is only valuable to the degree that utilities actually experience meaningful changes in the customer base. In this section, we describe the patterns of customer base growth and loss over the past two decades. Absent from most policy discussions about the energy transition is ex-post evidence on how utilities have historically managed customer base loss. We show that such experiences are commonplace, and we argue that important lessons can be drawn from these utilities.

\subsection{Preliminary Graphical Evidence}

Figure 1 plots residential customer counts over time for a random $4 \%$ of utilities. We normalize each utility's count to 1 at the beginning of the sample. As illustrated by the figure, there are widely differing experiences across utilities. Even though the U.S. population is growing, a substantial portion of utilities lose customers over this 22 -year period. There are many utilities that grow by $20 \%$ or more, but also many utilities that shrink by $20 \%$ or more.

The figure also reveals considerable persistence in both growth and loss. Recall that Table 1 shows that about half of all utility-year observations involve customer base loss; Figure 1 illustrates that this is not due to one-year "blips." For example, we observe around 320 utilities that experience five or more consecutive years of customer base growth, but also around 250 utilities that experience five or more consecutive years of customer base loss. 
Figure 1: We Observe Growing and Shrinking Utilities

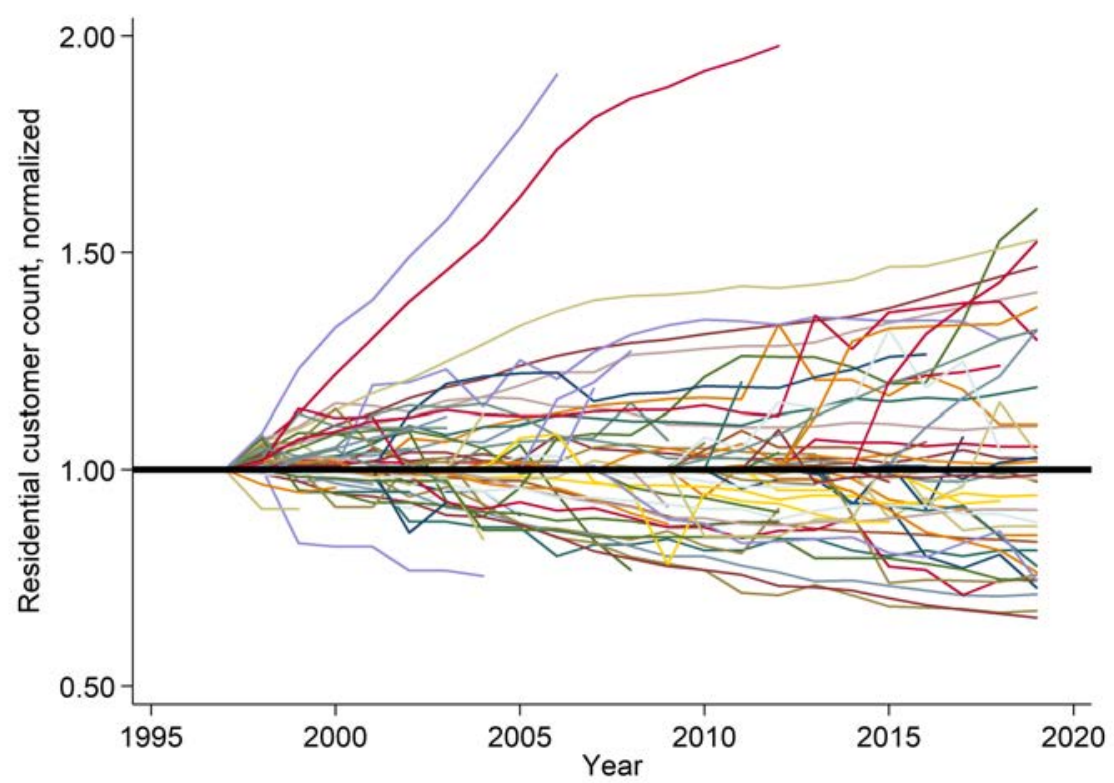

Note: This figure shows residential customer counts for a random $4 \%$ sample of utilities, normalized to 1 in their first year. Large changes have been assigned a new utility id to account for the possibility of mergers and acquisitions. The graph has been zoomed in to a maximum of 2.0 on the y-axis; the two utilities with the largest growth continued on an upward trend (not shown).

\subsection{Compositional Patterns}

To better understand the patterns driving these periods of growth and loss, we summarize in Table 2 the "proportion growing" variable across different utility types. Investor-owned utilities are more likely to be growing than are municipal utilities, but even for investorowned utilities more than one-quarter of utility-year observations are not growing. The high loss portion in municipally-owned utilities is likely related to rural depopulation in the U.S., discussed further below.

In addition, we find that medium and large utilities tend to be growing, while small utilities tend to be shrinking. For these statistics we measure the number of residential customers during the first year the utility appears in our sample. The proportion of all utility-year observations growing is monotonic across size categories, ranging from $92 \%$ for very large utilities to $31 \%$ for very small utilities.

Finally, we see a clear geographic pattern. The regions with the most customer growth include New England and the West ("Pacific" in the Census region nomenclature), with over 80 percent growth in each. The regions with the most customer loss include the South Atlantic and the Gulf Coast/Oklahoma/Texas area ("West South Central" in the Census 
Table 2: What Types of Utilities are Growing?

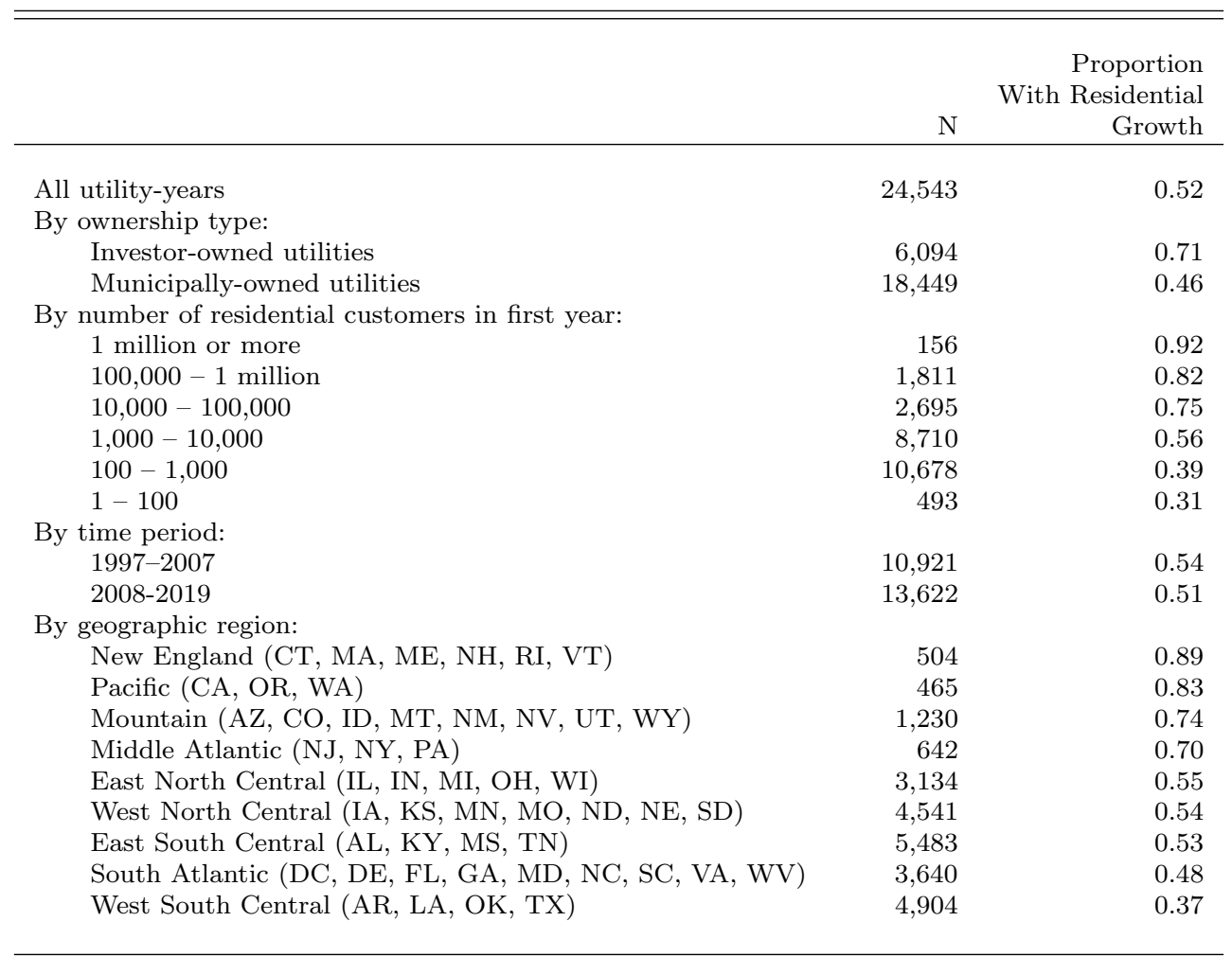

Note: This table describes our main estimation sample, classifying observations along several different dimensions. For each subset of the sample, the table reports the total number of utility-year observations as well as the proportion of utility-year observations for which the residential customer base grew.

region nomenclature). These geographic differences are difficult to interpret by themselves, because different regions have different utility sizes and different utility ownership patterns, for historical reasons. As such, we next analyze these regional differences separately for investor owned utilities and municipal utilities.

\subsection{Additional Geographic Evidence}

In Figure 2, we provide two maps aimed at better understanding the geographic pattern. We plot, at the state level, the proportion of utility-year observations with residential customer growth for investor owned utilities (Panel A) versus municipal utilities (Panel B). The high proportion of growth in New England reflects that the region is served only by investor-owned utilities and not by any municipal utilities. In contrast, the high proportion of growth in the Pacific region is seen in both the investor-owned and municipal utility maps.

These maps suggest that customer base changes are somewhat correlated with regional population changes. Western states such as New Mexico, Washington, Utah, Nevada and 
Figure 2: Regional Patterns in Residential Customer Base Changes

(a) Investor-Owned Utilities

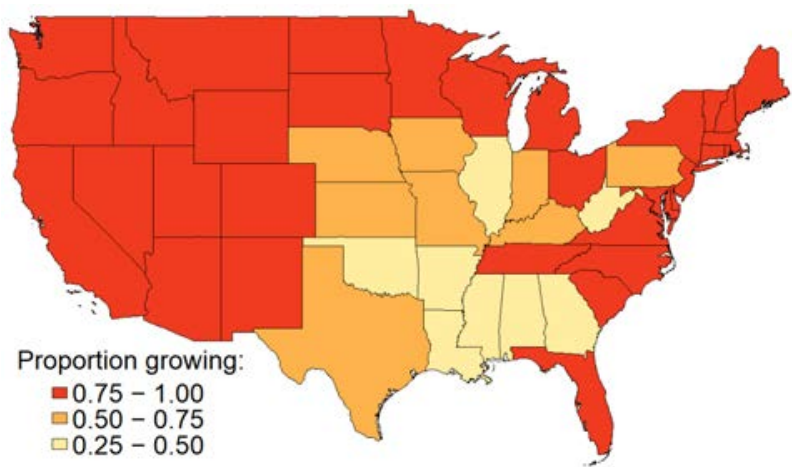

(b) Municipal Utilities

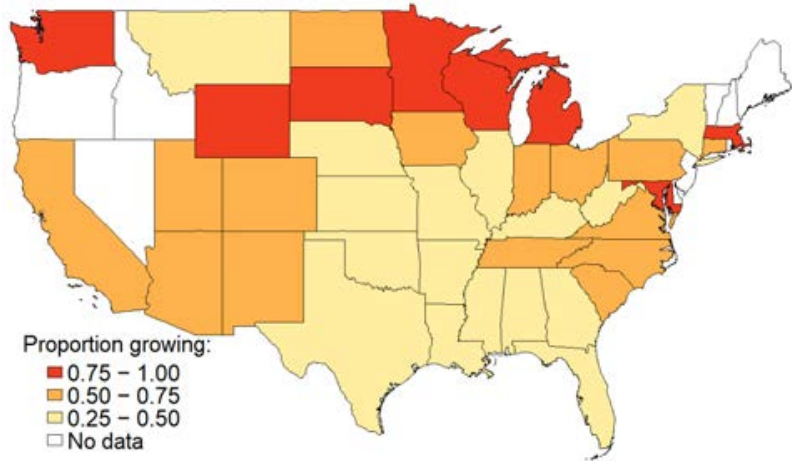

Note: These maps show by state the proportion of utility-year observations with residential customer growth separately for investor-owned and municipally-owned utilities. White states in panel (b) do not have any municipal utilities.

Idaho experienced growth at all investor-owned utilities in all years. Notably, all of these states also experienced substantial population growth over the 1997-2019 time period, with Nevada, Arizona, and Utah experiencing the largest population growth rates in the country. In contrast, West Virginia lost population over this time period, and Southern states like Mississippi and Louisiana had fairly slow population growth rates compared to much of the country.

To corroborate this pattern, we merged population estimates from the U.S. Census Bureau with the geographic boundaries of U.S. natural gas distribution utilities as of $2017 .{ }^{7}$ This exercise is imperfect because it fails to capture changes in service territory boundaries over time and because overlapping service territory boundaries and other issues introduce measurement error. Nevertheless, we are able to show using these merged data that population changes are highly correlated with changes in residential customer counts, particularly for larger utilities. Although there are many factors driving residential customer counts, it seems clear that population changes are the primary driver. See Appendix Table A3.

\subsection{Anecdotal Evidence from Selected Utilities}

The correlation between customer count changes and population changes matches anecdotes from several utilities. In a rate case filing for DTE - a large utility serving Detroit and Southeast Michigan - one analyst testified that "The poor local economic conditions in DTE Gas's service territory as well as declining population exacerbate the effect of declining sales in increasing the downside risk that DTE Gas may not be able to fully recover its

\footnotetext{
${ }^{7}$ Details in the Appendix.
} 
fixed costs." 8 National Fuel, serving upstate New York and parts of Pennsylvania (such as Pittsburgh) similarly argued that "it grapples with a declining population and a weak economy in its service territory." 9 A rate case for Centerpoint Arkla (Arkansas) discusses related challenges, with a growing number of pipeline miles but a decreasing number of customers: "declining revenues and increasing costs make it difficult, if not impossible, for the Company to recover its cost of service." 10

An especially compelling case study is that of Philadelphia Gas Works, the largest municipally-owned gas distribution utility in the country. A white paper details the financial struggles, noting: "The challenging demographics of PGW's customer base are a byproduct of Philadelphia's shrinking population and high concentration of poverty. The City has lost nearly 30 percent of its population over the past half-century." The report goes on to note implications for prices that we discuss further below: "with a declining customer base characterized by a high concentration of poverty, the need for additional price increases to cover fixed expenses seems inevitable."11

Municipal utilities tend to serve rural populations, and as such their customer base loss (with the exception of some urban utilities like Philadelphia Gas Works) may reflect rural depopulation. For this utility type, Cairo Public Utility Co of Illinois provides a clear case study. A series of news articles from 2017 summarizes the financial challenges facing this rural utility and the high bills facing its customers. As one of the articles notes, "[utility administrators] said that part of the issue with Cairo Public Utility Co. is that they are managing a system that was originally built for 20,000 people, and today Cairo is home to only about $2,500 . " 12$

In contrast to these anecdotes from rural areas, the Rust Belt, and parts of the Southeast, utilities in the Southwest and the West note a very different experience. For instance, the annual report for Southwest Gas (serving Arizona, Nevada, and California), notes "Southwest Gas remains among the top utilities for customer growth with 26,000 net new customer

${ }^{8}$ LARA Filing U-17999-0002. 18 December 2015. DTE Energy Company. Testimony, Case Number U17999. https://mi-psc.force.com/s/filing/a00t0000005pl9SAAQ/u179990002. Accessed 18 May 2021.

${ }^{9}$ Robinson, David. 8 November 2001. "NFG sees new pipelines as boost to U.S. security." Buffalo News. https://buffalonews.com/news/nfg-sees-new-pipelines-as-boost-to-u-s-security/ article_7eab74c6-5791-54fd-82a8-9034d7ecdca2.html. Accessed 2 February 2021.

${ }^{10}$ Docket No. 04-121-U. Filed 3 December 2004. http://www. apscservices.info/pdf/04/04-121-u_ 35_1.pdf. Accessed 2 February 2021.

${ }^{11}$ Economy League of Greater Philadelphia. 2008. "The Philadelphia Gas Works: Challenges and Solutions." https://www .pewtrusts.org/en/research-and-analysis/reports/2008/10/21/ the-philadelphia-gas-works-challenges-and-solutions. Accessed 18 May 2021.

${ }^{12}$ Smith, Isaac. 26 July 2017. "For citizens and business owners, high utility bills are a way of life in Cairo." The Southern. https://thesouthern.com/news/local/ for-citizens-and-business-owners-high-utility-bills-are-a-way-of-life-in-cairo/article_ 103a8531-55bd-54a3-9415-3fae8a319ef6.html. Accessed 3 February 2021. 
additions in 2015. This is due in part to a growing economic recovery across Southwest Gas service territories," going on to describe how projected population growth rates in its major metro areas are much higher than for the U.S. as a whole. ${ }^{13}$ Similarly, Questar Gas's annual report notes "The population of the Company's service area in Utah continues to grow faster than the national average." 14

Overall, the main takeaway is that many U.S. natural gas utilities have faced years of customer base loss. This is especially true of small utilities and of municipal utilities, and a major factor appears to be population changes. The experience of these utilities might be informative as policies seek to transition building energy use from natural gas to electricity. We next turn to an empirical examination of utility operations and finances.

\section{Results}

\subsection{Pipelines}

We begin by examining the relationship between the physical pipeline network and the number of customers. Figure 3 plots the relationship between the log change in pipeline miles and the log change in residential customer counts. The figure also shows a histogram of log residential customer count changes - matching the summary statistics in Table 2, the histogram shows that roughly half of residential customer changes are positive and half are negative. ${ }^{15}$

A clear positive relationship emerges in Figure 3. As utilities grow, they add pipelines. However, a clear asymmetry is also visible. In addition to the scatterplot (with markers sized by initial utility size), we overlay a lowess smoother. Importantly, this lowess smoother does not impose any asymmetry - but one emerges naturally. With growth in the residential count, i.e. on the right-hand side of the plot, there is an upward sloping, nearly linear fit between the log growth in miles and the log growth in residential customers. With loss in the customer count, i.e. on the left-hand side of the plot, there is essentially no change in the log mile count. There is a slight upward tick on the far left side of the plot, but there are almost no observations in that region, as shown in the histogram along the bottom. In contrast, there is a substantial mass of observations closer to the origin, i.e. at around zero

\footnotetext{
${ }^{13}$ Southwest Gas 2015 Annual Report. https://www.swgas.com/www/flipbooks/Swgas_Annual_ Report_2015/mobile/index.html\#p=2. Accessed 18 May 2021.

${ }^{14}$ Questar Gas 1999 Annual Report. https://www.sec.gov/Archives/edgar/data/68589/ 0000068589-99-000002.txt. Accessed 18 May 2021.

${ }^{15}$ In the Appendix, we show a histogram for the change in log miles. Five percent of observations involve a reduction in $\log$ miles from one year to the next; these observations have a median log change of -0.006 .
} 
Figure 3: The Asymmetric Relationship Between Pipelines and Customers

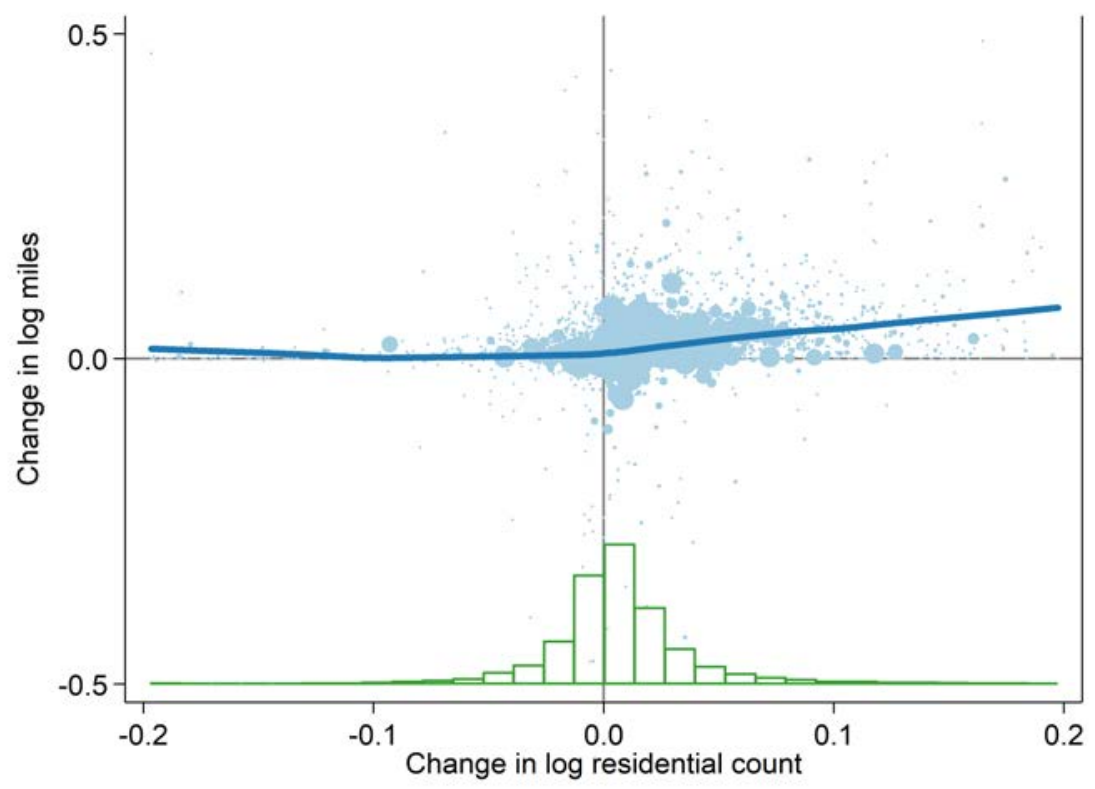

Note: The thick dark line shows a lowess fit. The lowess has been fit to the full estimation sample, but the scatter plot is zoomed in to $[-0.5,0.5]$ on the $\mathrm{y}$-axis to make the lowess slope more visible. A histogram for changes in residential counts is included at the bottom of the figure.

to five log points of loss. Typically when a utility loses a small percentage of customers, it experiences no change in its pipeline miles.

We next formalize this intuition with two sets of regressions. First, we regress the log change in pipeline miles on the log change in residential and commercial customer counts. The regression takes the form:

$$
\Delta \ln M_{i, t}=\alpha+\beta \Delta \ln R_{i, t}+\gamma \Delta \ln C_{i, t}+\varepsilon_{i, t}
$$

where $M_{i, t}$ is the miles of pipeline mains at utility $i$ in year $t, R$ is the count of residential customers, and $C_{i, t}$ is the count of commercial customers. Standard errors are clustered by utility to account for serial correlation.

We use logs to ease comparisons across large and small utilities. We use differencing because we are interested in what happens as utilities grow or shrink, rather than in crosssectional differences between large and small utilities. One could instead use fixed effects, which we show in the Appendix. In our baseline specification, we do not use any controls; as we do not expect there to be factors that require a utility to grow its pipeline network other than the growth of its customer base, but we examine specifications with additional controls in the Appendix. 
Table 3, Column 1 shows the estimation results for Equation 1. A ten percent increase in the residential customer count is associated with a roughly 2.5 percent increase in pipeline miles, statistically significant at the one percent level. A ten percent increase in the commercial customer count is associated with a 0.3 percent increase in pipeline miles, statistically significant at the one percent level. The magnitude difference between the residential and commercial estimates is intuitive: as shown in the Appendix, the typical utility has 10 times as many residential customers as commercial customers, so a one percent change in residential customers is a much larger change in customers than is a one percent change in commercial customers. This can be seen by looking at level effects of the estimates at the median values. The elasticity of 0.25 for residential customers translates into 1.1 miles for every 100 residential customers, as shown at the bottom of the table. The elasticity of 0.03 for commercial customers translates into 1.3 miles for every 100 commercial customers (not shown, for space).

\subsection{Asymmetric Impacts}

The first regression results, however, mask important differences between periods of customer base growth and loss. Once a pipeline is built, a utility is unlikely to remove it, or to stop selling gas via it. This is particularly true if customer base loss is geographically dispersed, for instance if driven by urban vacancy rates.

We next estimate an asymmetric specification, allowing for differential impacts of customer growth and loss:

$$
\Delta M_{i, t}=\alpha+\sum_{s \in R, C} \beta_{s}^{+}\left(\Delta N_{i, t}^{s}\right)^{+}+\sum_{s \in R, C} \beta_{s}^{-}\left(\Delta N_{i, t}^{s}\right)^{-}+\sum_{s \in R, C} \eta_{s} \mathbf{1}\left(\Delta N_{i, t}^{s}\right)^{+}+\varepsilon_{i, t} .
$$

For the sake of brevity, we omit "In" in the equation above but all variables are in logs as in Equation 1. The dependent variable $\Delta M_{i, t}$ is again the log change in pipeline miles for utility $i$ in year $t$. The coefficient $\beta_{s}^{+}$is the impact of the log change in customer counts for sector $s$ (residential or commercial) at utility $i\left(\Delta N_{i, t}^{s}\right)$ when the log change is strictly positive, and $\beta_{s}^{-}$is the impact when the log change is weakly negative. Because $\left(\Delta N_{i, t}^{s}\right)^{+}$is an interaction term between the log change in customer counts $\Delta N_{i, t}^{s}$ and an indicator for whether than change is positive, we also include this indicator on its own: $\mathbf{1}\left(\Delta N_{i, t}^{s}\right)^{+}$. We expect the coefficient on this indicator to be close to zero, as we do not expect a differential change in miles for utilities with very slightly positive versus very slightly negative customer count changes.

Results are presented in the second column of Table 3. In keeping with the Figure 3, this 
Table 3: The Impact of Customer Base Changes on Pipeline Infrastructure

\begin{tabular}{|c|c|c|}
\hline & $\begin{array}{c}(1) \\
\text { Pipeline Miles (log) }\end{array}$ & $\begin{array}{c}(2) \\
\text { Pipeline Miles (log) }\end{array}$ \\
\hline Residential customers (log) & $\begin{array}{c}0.249^{* * *} \\
(0.023)\end{array}$ & \\
\hline Commercial customers (log) & $\begin{array}{c}0.034^{* * *} \\
(0.011)\end{array}$ & \\
\hline Residential customers (log), when growing & & $\begin{array}{c}0.385^{* * *} \\
(0.037)\end{array}$ \\
\hline Residential customers (log), when shrinking & & $\begin{array}{l}-0.001 \\
(0.039)\end{array}$ \\
\hline Commercial customers (log), when growing & & $\begin{array}{c}0.028 \\
(0.020)\end{array}$ \\
\hline Commercial customers (log), when shrinking & & $\begin{array}{l}-0.007 \\
(0.016)\end{array}$ \\
\hline Constant & $\begin{array}{c}0.011^{* * *} \\
(0.000)\end{array}$ & $\begin{array}{c}0.003^{* * *} \\
(0.001)\end{array}$ \\
\hline $\begin{array}{l}\text { Observations } \\
\mathrm{R}^{2}\end{array}$ & $\begin{array}{c}9,538 \\
0.04\end{array}$ & $\begin{array}{c}9,538 \\
0.06\end{array}$ \\
\hline Miles per 100 residential customers & 1.09 & \\
\hline When growing & & 1.68 \\
\hline When shrinking & & -0.01 \\
\hline P-value: null of symmetry & & \\
\hline Residential & & 0.00 \\
\hline Commercial & & 0.18 \\
\hline Combined & & 0.00 \\
\hline
\end{tabular}

Note: This table shows point estimates and standard errors corresponding to two separate least squares regressions. In both columns the dependent variable is the total number of miles of pipeline mains in logs. The regressions are estimated in differences. The p-value rows show the results of tests that the growing and shrinking coefficients are equal to one another. The "miles per 100 customers" rows show the marginal effects at the median values of the dependent variable and the median customer count. The sample includes annual observations from 1997 to 2019, with around 400 utilities per year. Residential customer log changes of more than 0.2 (in absolute value) and commercial log changes of more than 0.5 (in absolute value) are dropped, as they likely indicate service territory changes. The sample is limited to periods when the utility grew or shrank for two or more consecutive years, matching the policy thought experiment in the paper. Alternative samples and specifications are shown in the Appendix. Standard errors are clustered by utility.

specification shows statistically and economically significant asymmetry in the impact of a changing customer base on pipeline infrastructure. A ten percent increase in the number of residential customers is associated with a 3.9 percent increase in pipeline length. This coefficient is precisely estimated, and statistically different from 0.25 , the coefficient in Column 1. In contrast, for decreases in the number of residential customers, the typical utility sees essentially no decrease in the number of miles; the coefficient is -0.001 and is not statistically different from zero. As shown at the bottom of the table, symmetry can be rejected at the one percent level for the residential specification. As in the symmetric specification, the coefficient for commercial count growth is fairly small; and again, there's essentially no 
response for commercial loss.

The evidence in Table 3 implies less than one-for-one pipeline growth in response to residential customer increases. This is somewhat surprising. However, there are several likely explanations. First, residential customers do not make up all of the utility network; one must also consider commercial customers. That is, when a utility grows its residential customer base by one percent, it is not growing its entire customer base by one percent. So, a test of the linear combination across sectors is a more appropriate comparison. Second, some of the time when utilities are growing, they are adding customers to existing neighborhoods, and therefore not constructing new pipelines. Finally, there may be differences in the timing of when utilities measure the addition of new pipelines versus the addition of new customers (e.g., year-end versus mid-year). In the Appendix, we consider long-run estimates that address these latter two potential explanations, using an error correction model. The longrun results again show an asymmetry, with a larger coefficient when growing (0.65) and a near-zero coefficient when shrinking.

Finally, it is worth noting that the constant is positive and statistically significant in both columns. The positive constant implies that even a utility with flat residential and commercial counts tends to see a modest increase in pipeline miles. This is consistent with some churn within the service territory, for instance if urban customers leave the city center to move to new suburban developments within the same utility's service territory.

\subsection{Finances}

We next perform a similar analysis using data on utility revenues. Utilities collect revenue from customers to pay for capital and operating costs, and we want to understand how these revenues respond to changes in the customer base. Part of our motivation for the paper is that many categories of utility expenditures are likely to be "legacy costs" that do not necessarily disappear as customers leave the system.

We use regression specifications very similar to the specifications used for pipeline miles. Specifically, we regress net revenue (total revenue collected minus gas costs, as described above) on customer counts. We begin with a symmetric specification, as in Equation 1 and then proceed to an asymmetric specification, as in Equation 2. As with the pipeline analysis, we drop large changes in customer counts that likely indicate mergers, acquisitions, etc.

These specifications differ from the estimation with pipeline miles in a few ways. First, our sample size is larger, as we can now include the utilities for which we were unable to merge the EIA data on customer counts and revenues with the PHMSA data on pipeline

miles. Second, because we observe net revenue separately for the residential and commercial 
sectors (whereas we only observed combined miles), we can now estimate separate regressions by sector.

These regressions are designed to ask "if the customer base grows or shrinks, while weather remains unchanged and while the quantity sold to the typical customer remains unchanged, what happens to a utility's revenue net of gas costs?" Accordingly, we introduce three new control variables. We include the log change in quantity sold per customer (also in differences). Utility net revenues are directly impacted by changes in quantity, as the typical utility includes a substantial per-unit mark-up to cover fixed costs. As a result, exogenous changes in quantity consumed per customer as a result of weather changes or economic shocks can substantially change net revenues. In addition, we include weather, both heating degree days and cooling degree days (also in differences). Together, this quantity sold variable and the two weather variables assist in two ways. First, they reduce noise in the net revenue variable and thus improve the precision of our estimates. Second, it is possible that new customers and departing customers have different consumption patterns. Thus growing or shrinking the customer base could change the average quantity sold and thus net revenues. By controlling for quantity sold per customer, our primary specification purges our estimates of the customer base impact of this effect on average.

Results are shown in Table 4 (for brevity, we display only the coefficients on customer counts; point estimates on the control variables are shown in the Appendix, Table A6). The first column shows that a ten percent change in residential customers is associated with a roughly 6.5 percent change in residential net revenue. The estimate in Column 2 is slightly higher for commercial. These estimates translate into roughly $\$ 200$ of net revenue per residential customer and $\$ 1,000$ per commercial customer.

Columns 3 and 4, however, show marked asymmetry, particularly for residential customers. Although the point estimates suggest less asymmetry for commercial customers, the standard errors are wide enough that we are hesitant to draw strong distinctions between customer classes. A utility that adds ten percent more residential customers increases its net revenue by ten percent; an elasticity of one. This translates into $\$ 328$ per customer (as shown at the bottom of the table), roughly matching the median net revenue per customer in our sample (Table 1). This is intuitive if utilities do not change their pricing structure when they are growing, so that new customers translate directly into new revenues.

In contrast, a utility that experiences a ten percent decrease in residential customers decreases its net revenue by only five percent. It is intuitive that this is not equal to zero (and is statistically different from zero at the five percent level), since costs may fall when a customer departs. These may represent falling costs of service provision (e.g., meter reading becomes easier with fewer customers), or they may represent decreased returns to investors, 
Table 4: The Impact of Customer Base Changes on Net Revenue

\begin{tabular}{|c|c|c|c|c|}
\hline & $\begin{array}{c}(1) \\
\text { Residential } \\
\text { Net Revenue }\end{array}$ & $\begin{array}{c}(2) \\
\text { Commercial } \\
\text { Net Revenue }\end{array}$ & $\begin{array}{c}(3) \\
\text { Residential } \\
\text { Net Revenue }\end{array}$ & $\begin{array}{c}(4) \\
\text { Commercial } \\
\text { Net Revenue }\end{array}$ \\
\hline Customers (log) & $\begin{array}{c}0.65^{* * * *} \\
(0.09)\end{array}$ & $\begin{array}{c}0.75^{* * * *} \\
(0.06)\end{array}$ & & \\
\hline Customers (log), when growing & & & $\begin{array}{c}1.01 * * * \\
(0.13)\end{array}$ & $\begin{array}{c}0.86^{* * *} \\
(0.10)\end{array}$ \\
\hline Customers (log), when shrinking & & & $\begin{array}{c}0.47^{* *} \\
(0.20)\end{array}$ & $\begin{array}{c}0.77 * * * \\
(0.11)\end{array}$ \\
\hline Constant & $\begin{array}{l}0.00^{*} \\
(0.00)\end{array}$ & $\begin{array}{l}0.00^{*} \\
(0.00)\end{array}$ & $\begin{array}{c}0.00 \\
(0.01)\end{array}$ & $\begin{array}{c}0.01^{* *} \\
(0.01)\end{array}$ \\
\hline Observations & 14,437 & 14,017 & 14,437 & 14,017 \\
\hline $\mathrm{R}^{2}$ & 0.02 & 0.08 & 0.02 & 0.08 \\
\hline Dollars per customer & 211 & 988 & & \\
\hline When growing & & & 328 & 1137 \\
\hline When shrinking & & & 152 & 1015 \\
\hline P-value: null of symmetry & & & 0.02 & 0.53 \\
\hline
\end{tabular}

Note: This table reports point estimates and standard errors corresponding to four separate least squares regressions. The dependent variable in Columns (1) and (3) is net revenue from the residential sector, in logs. The dependent variable in Columns (2) and (4) is net revenue from the commercial sector, in logs. The regressions are estimated in differences. The p-value rows show the results of tests that the growing and shrinking coefficients are equal to one another. The "dollars per customer" rows show the marginal effects at the median values of the dependent variable and the median customer count. The sample includes annual observations from 1997 to 2019, with around 600 utilities per year. Residential customer log changes of more than 0.2 (in absolute value) and commercial log changes of more than 0.5 (in absolute value) are dropped, as they may indicate service territory changes. The sample is limited to periods when the utility grew or shrank for two or more consecutive years, matching the policy thought experiment in the paper. Alternative samples and specifications are shown in the Appendix. Standard errors are clustered by utility.

as we discuss below.

However it is also important to note that the growing and shrinking estimates are statistically different from one another at the five percent level, as shown in the bottom row of the table. In level terms, losing one customer translates into a revenue decrease of $\$ 152$, whereas gaining one customer translates into a revenue increase of $\$ 328$. That is, utilities with shrinking customer bases do not experience shrinking revenues at a one-for-one rate. This asymmetry is interesting and important because it indicates that utility shareholders are not bearing the full brunt of legacy costs. With shrinking utilities, it appears that ratepayers are bearing a large share of these costs - consistent with utilities raising prices to increase total revenue collection per customer for those customers who continue to receive natural gas service.

A hypothetical numerical example is helpful. Suppose a utility initially has 10,000 customers and collects $\$ 300$ per customer each year, so that its net revenue is $\$ 3$ million. It then 
loses five percent of its residential customer base, i.e. 500 customers. If prices didn't change, net revenue would be $\$ 2.85$ million. But according to the estimates in Table 4 , the utility's residential net revenue would decrease by 2.5 percent, leaving it with a net revenue of $\$ 2.925$ million. This translates into $\$ 308$ per customer - prices for the remaining customers have risen by about 2.5 percent. We further explore this under future potential scenarios below.

\subsection{Robustness Checks and Additional Specifications}

In the Appendix, we show a large number of robustness checks and additional specifications, ultimately concluding that our results on the impacts of a changing customer base on pipeline miles and on net revenue collected are robust.

Results for the impact of customer base changes on pipeline miles are shown in Table A4. We include utilities with a large fraction of retail choice customers; this adds around 300 observations but essentially does not change the point estimates. We next include large year-on-year customer changes that likely indicate mergers, acquisitions, etc.

We next include one-year periods of growth or loss. This has the greatest impact on our observation count of any robustness check - in the raw data, many utility-year observations are one-year blips in either customer growth or customer loss. This is especially true because we drop the observations that experience such a blip in either the residential or the commercial sector. The robustness check that includes these one-year periods yields qualitatively similar coefficients and conclusions. Most importantly, the asymmetry we see in customer growth or loss is still notable in this robustness check. The coefficient on residential customer growth is somewhat smaller, which is intuitive if pipeline miles do not need to grow in response to one-year blips that do not represent sustained customer growth.

We include utilities with small mile counts, which somewhat attenuates the coefficient on growing miles but does not change our conclusions about asymmetry. ${ }^{16}$ We next include large changes in miles that may indicate measurement error. Alternatively, we use a more stringent definition of outliers in this variable.

We next limit the sample just to investor-owned utilities, dropping municipal utilities. Alternatively, we limit the sample to medium and large utilities, i.e. those with at least 10,000 residential customers in every year. Next we include the additional weather and quantity-per-customer controls that we include in the net revenue specifications. Next we add either year effects or fixed effects, while still estimating the regression in differences.

Across all of these additional specifications, we continue to find an asymmetric impact of customer base changes on miles. The estimates for residential customer growth are all

\footnotetext{
${ }^{16}$ This is explored in greater depth in Table A5.
} 
qualitatively similar, and all specifications have comparable statistical significance. The impact of customer loss is generally close to zero. The one exception is the specification that limits the sample to investor-owned utilities. For that specification, we are unable to precisely estimate the impact of residential customer loss because, as we show in Table 2, most investor-owned utilities are growing over our sample period.

We similarly estimate several additional specifications for the net revenue variable, concluding that our main results are robust (Tables A7 and A8). We estimate regressions using alternative samples as we did for the miles specification (e.g., including retail choice, limiting to investor-owned utilities, etc.). In addition, we include a specification that has both residential and commercial counts on the right-hand side; a specification with an alternative net revenue measurement; and a specification that limits the sample to just those utilities for which we observe pipeline miles. Across this broad suite of robustness checks, we continue to estimate a coefficient close to 1 when residential customer count is growing and a coefficient of around 0.5 when the residential customer count is shrinking. As with the miles specification, we lose power on the shrinking coefficient when we limit to investor-owned utilities; we also lose power when we limit to large utilities, or when we add fixed effects (akin, in this differences specification, to utility-specific trends). Commercial results are similarly robust across these additional specifications.

To summarize, we show that growing utilities add new pipeline infrastructure, but utilities with shrinking customer bases continue to maintain the same amount of legacy pipeline infrastructure. In keeping with this, utility revenues rise (with an elasticity of one) when the customer base grows, but shrink by a smaller amount when the customer base shrinks. That is, prices for remaining customers rise. We next turn to a discussion of the implications for equity across customers as well as an examination of utility expenditures.

\section{$5 \quad$ Discussion and Policy Implications}

\subsection{Income and Racial Equity}

Increasing prices for remaining customers at a shrinking utility will clearly have equity implications. This is true both historically, for the customer base shrinking that we observe in our sample, and in the future, for example, with customers leaving the utility due to building electrification. As customers leave natural gas service, they stop paying for the pipeline infrastructure that they leave behind. How this interacts with income, racial, or other inequality depends on the characteristics of the customers who leave, as well as on the characteristics of the customers who get left behind. 
Table 5: Demographic Characteristics of Shrinking and Growing Utilities

\begin{tabular}{|c|c|c|c|c|c|c|c|c|}
\hline State & Utility & $\begin{array}{r}\text { Initial } \\
\text { Residential } \\
\text { Count }\end{array}$ & Change & $\begin{array}{l}\text { Largest } \\
\text { City } \\
\text { Served } \\
\end{array}$ & $\begin{array}{r}\text { Pop. } \\
\text { Change } \\
2000-19 \\
\end{array}$ & $\begin{array}{l}\text { Percent } \\
\text { Black or } \\
\text { Afr-Am. }\end{array}$ & $\begin{array}{l}\text { Pov- } \\
\text { erty } \\
\text { Rate } \\
\end{array}$ & $\begin{array}{r}\text { Income } \\
\text { Per Cap. } \\
\$ 000 \text { 's }\end{array}$ \\
\hline \multicolumn{9}{|c|}{ Panel A: Utilities with largest customer loss: } \\
\hline $\mathrm{AL}$ & Alabama Gas Corp & 423,130 & $-29,865$ & Birmingham & -13 & 70 & 26 & 24 \\
\hline AR & Centerpoint Energy Arkla & 386,572 & $-25,949$ & Little Rock & 8 & 42 & 17 & 36 \\
\hline $\mathrm{AL}$ & Spire Gulf Inc & 95,021 & $-16,279$ & Mobile & -7 & 52 & 21 & 27 \\
\hline OK & Centerpoint Energy Arkla & 100,850 & $-13,385$ & Lawton & 0 & 20 & 19 & 24 \\
\hline $\mathrm{PA}$ & Philadelphia Gas Works & 492,945 & $-10,100$ & Philadelphia & 5 & 42 & 24 & 28 \\
\hline WV & Hope Gas Inc & 111,216 & $-9,553$ & Charleston & -13 & 16 & 21 & 35 \\
\hline LA & Centerpoint Energy Entex & 116,781 & $-9,085$ & Shreveport & -6 & 57 & 26 & 26 \\
\hline GA & Albany Wtr Gas Lt Comm & 16,298 & $-5,864$ & Albany & -7 & 74 & 31 & 20 \\
\hline \multicolumn{9}{|c|}{ Panel B: Utilities with largest customer gain: } \\
\hline IL & Nicor Gas & $1,722,299$ & 342,511 & Aurora & 37 & 10 & 11 & 31 \\
\hline NV & Southwest Gas Corporation & 337,465 & 393,567 & Las Vegas & 35 & 12 & 15 & 31 \\
\hline UT & Questar Gas Company & 560,717 & 411,496 & Salt Lake City & 10 & 3 & 17 & 37 \\
\hline $\mathrm{CO}$ & Pub Service Co Of Colorado & 889,902 & 419,749 & Denver & 31 & 9 & 13 & 44 \\
\hline $\mathrm{AZ}$ & Southwest Gas Corporation & 598,050 & 453,019 & Phoenix & 27 & 7 & 18 & 29 \\
\hline $\mathrm{TX}$ & Centerpoint Energy Entex & $1,103,814$ & 545,829 & Houston & 18 & 23 & 20 & 33 \\
\hline CA & Pacific Gas & $3,493,097$ & 791,719 & San Jose & 13 & 3 & 9 & 47 \\
\hline $\mathrm{CA}$ & Southern California Gas & $4,599,840$ & $1,007,849$ & Los Angeles & 8 & 9 & 18 & 35 \\
\hline
\end{tabular}

Note: This table describes the eight natural gas utilities in our sample which experienced the largest loss in residential customers along with the eight utilities which experienced the largest gain in residential customers from 1997 to 2019 . Columns 3 and 4 list the initial count of residential customers and the change in residential customers over our sample, respectively. The last four columns provide demographic statistics from the U.S. Census Bureau for the largest city served by each utility.

Table 5 describes the eight utilities which experienced the largest loss in residential customers as well as the eight utilities which experienced the largest increase in residential customers. These sixteen utilities are generally large utilities (almost all have more than 100,000 residential customers at the beginning of our sample, and the largest serves more than 4 million residential accounts). They are generally investor-owned utilities, with the exception of the municipally-operated Philadelphia Gas Works and a municipal utility in Albany, Georgia. And, they generally experienced prolonged periods of either growth or loss over our time period, as opposed to one-time changes (Appendix Figure A2).

For each utility, we list the largest city served, according to the utility's website. Our data is at the utility level, not household level, and we do not have demographic or socioeconomic information about the composition of customers who exit or enter natural gas service, nor do we have comprehensive information on service territories over time. Nonetheless, broader city-level demographic and socioeconomic information for the largest city served can shed light on the type of communities that have experienced customer loss and gain.

We list four demographic characteristics for each city: the population change over the 2000-2019 period, the percentage of the city's population that is Black or African-American, 
the poverty rate, and the annual per capita income (in thousands of dollars). ${ }^{17}$

There are several striking features of Table 5. First, the utilities with the largest customer losses generally serve cities with declining or flat populations. Several cities experienced large losses in population: Birmingham, Alabama and Charleston, West Virginia, each with a drop of 13 percent; also Mobile, Alabama; Albany, Georgia; and Shreveport, Louisiana. In contrast, the utilities with the largest customer gains generally served cities with growing populations: Aurora, Illinois experienced a 37 percent increase in population and Las Vegas 35 percent. The growing utilities nearly all serve states in the West and Southwest, consistent with regional demographic trends in the U.S. over this time period.

Second, the utilities with large customer losses overwhelmingly serve cities with large African-American populations. With the exceptions of Charleston, WV and Lawton, OK, the largest cities served by the shrinking utilities have populations that are 40 percent or more African-American. In contrast, the utilities with growing customer bases generally serve cities with much smaller African-American populations. A number of economic and social forces may be at play here; Beauregard (2009) identifies several factors responsible for shrinking cities over the 1980-2000 period, including suburbanization, racial antagonisms, and more. For instance, one important force behind migration in the U.S. has been White flight and suburbanization, the latter frequently racially restricted. While most work has emphasized the post-War period, Crowder and South (2008) and Beauregard (2009) suggest this legacy continues in more recent decades. Future work could look at whether historical White flight has led to a stranded pipeline infrastructure that must be maintained by the remaining African-American population.

Table 5 also shows a pattern of income inequality that is correlated with shrinking or growing customer bases. The median poverty rate in the large cities served by shrinking utilities is 23 percent, and the median rate for the growing utilities is 16 percent. Similarly, the median per-capita income in the shrinking sample is $\$ 27,000$, compared to $\$ 34,000$ in the growing utilities. This pattern matches that explored by Faust, Abraham and McElmurry (2016), who examine water infrastructure management in four shrinking cities. They focus on the Rust Belt and not the South, but like us, show that the shrinking cities have low incomes, and therefore "shrinking cities face not only a decline in [water] customers but also the inability of the existing customers to afford drastically increasing rates" (p. 133). The pattern is also consistent with the vicious cycle of urban economic decline described by both Faust, Abraham and McElmurry (2016) and Galster (2017); the latter writes that "selective outflow renders the city increasingly occupied by the disadvantaged," noting also that "[o]ut-

\footnotetext{
${ }^{17}$ The socioeconomic variables are reported at the city level by the Census Bureau using data from the American Community Survey five-year estimates; we report vintage year 2019 estimates.
} 
mobility of disadvantaged households who are African-American or Latino may be further constrained by illegal discrimination in housing markets outside of declining cities" (p. 357).

The evidence on mostly larger, mostly urban utilities in Table 5 complements the evidence shown earlier on declining residential customer counts for municipal utilities (Table 2), which are typically small and rural. This customer base loss for municipalities is intuitive given the rural depopulation of much of the United States. As Johnson and Lichter (2019) write, "[p]opulation loss has seemingly become the new demographic norm across broad regions of rural America" (p 4).

Overall, we highlight three equity-related implications of our work. All three are suggestive, but future work could explore these on a national scale. First, we show patterns of customer base loss in predominantly African-American cities, which may contribute to higher energy bills for urban African-American populations. Second, rural depopulation may also lead to a rural/suburban divide in energy bills and infrastructure quality. Finally, if future electrification leads to inequality in energy expenditures (an issue we next explore in depth), it may be worth investigating how these future issues interact with the past inequities described above.

\subsection{Simulating Bill Impacts of Customer Exit}

As we discuss above, building electrification is emerging as a central policy issue for climate change mitigation. Our results point to a thorny issue during a transition period in which some, but not all, buildings electrify. If building electrification occurs in a geographically dispersed manner, utilities will need to continue to pay for pipeline networks but will have fewer customers to bear these costs. As we show above, shrinking customer bases lead to rising prices for remaining customers, with implications for equity. In this section, we explore potential price impacts in greater detail. We focus on the residential sector, for which the equity implications are clearest, but we note that similar mechanisms are at play in the commercial sector. We assume throughout this analysis that there is no cross-subsidization across sectors, i.e. the revenue requirement in the residential sector does not depend on what occurs in the commercial sector, consistent with traditional utility practice.

In Figure 4 we plot (thick, middle line) the implications of the estimates from Table 4 for a rise in prices under different magnitudes of natural gas customer exit. Specifically, in a scenario in which zero percent of residential natural gas customers exit, we assume the typical customer pays $\$ 328$ per year in net revenue. ${ }^{18}$ Then we assume that each one percent

\footnotetext{
${ }^{18} \$ 328$ is our estimate for net revenue at growing utilities in Table 4; it is also similar to the median residential net revenue value of $\$ 350$ in Table 1 .
} 
Figure 4: Utility Bills Rise Non-Linearly With Customer Exit

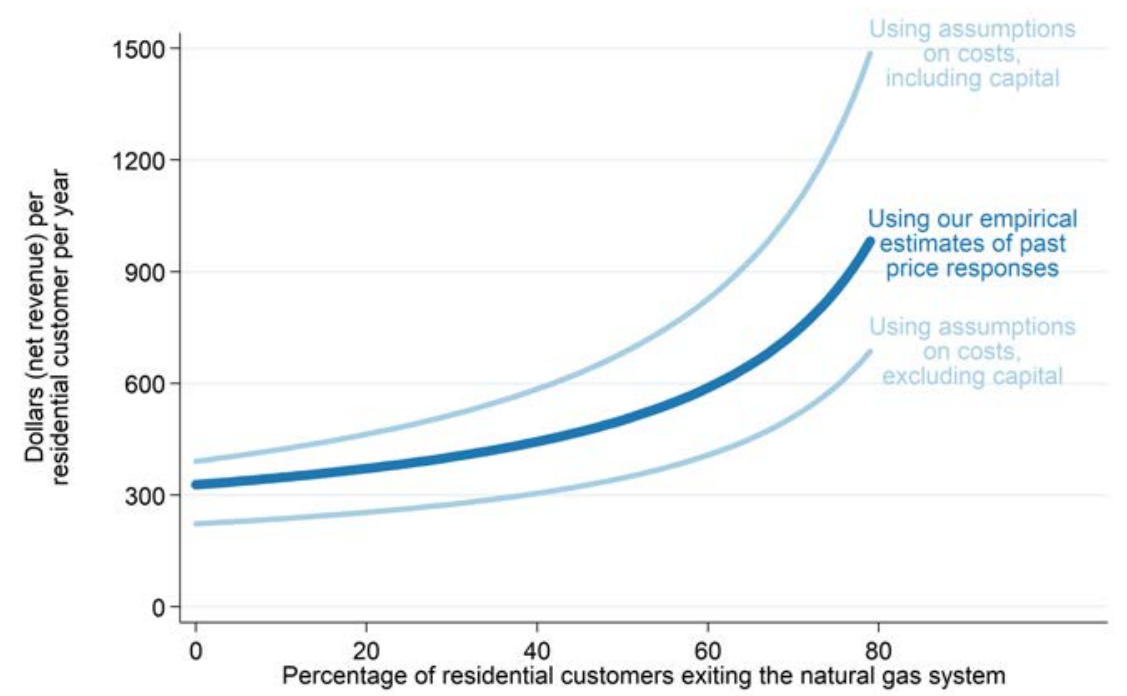

Note: This figure plots how the net revenue per residential customer (that is, bill totals net of gas costs) changes as other customers exit, for instance because they switch to electric heating and cooking. The thick, middle line uses empirical estimates from past utility behavior, specifically the estimates in Table 4. The top and bottom lines provide approximate bounds for these estimates, calculated based on financial data from a sample of utilities as described in Section 5.3. The upper and lower bounds reflect a representative utility at the beginning and end of the depreciation schedule, respectively. If gas costs were included, it would simply shift all three lines up by a constant amount, equal to around $\$ 300$ per customer per year (Table 6) but fluctuating with weather, macroeconomic conditions, and natural gas wholesale prices.

of lost gas customers leads to a 0.53 percent rise in prices for everyone else, based on the 0.47 coefficient in Column 3 of Table 4.

Figure 4 shows that bill impacts are small when only a small percentage of customers exit the natural gas sector, but increase substantially as a higher percentage of customers exit. To understand why this relationship is non-linear, imagine that all customers but one exit, and that remaining customer must cover all of the utility's legacy costs. Recent papers on U.S. economy-wide decarbonization assume a rapid electrification of residential buildings (Aas et al., 2020; Larson et al., 2020; National Academies of Sciences, Engineering, and Medicine, 2021; Williams et al., 2021). Larson et al. (2020) and Williams et al. (2021) assume something on the order of a 15 percent reduction in natural gas residential customers by 2030 and 40 percent or more by 2040. Our estimates imply that customer exit of this level this would translate into annual bill increases of $\$ 31$ and $\$ 116$ per customer, respectively. These higher natural gas bills will then prompt additional customer exit, in the natural gas 
version of the "utility death spiral."19

This general pattern is similar to previous calculations by policy analysts. Gridworks (2019) calculates a roughly 100 percent increase in residential natural gas bills for a 60 percent decrease in residential gas demand in California (although note that figure includes gas commodity costs, which we have not included). As another point of comparison, a CEC analysis (Aas et al., 2020) describes a scenario in which prices increase by 80 percent by 2030 and 480 percent by 2050, although that includes other cost drivers too.

Nonetheless, it is important to emphasize that these calculations are based on our empirical analysis of past customer losses. However, under a transition away from natural gas, the composition of customer exit could be quite different from the historical pattern. Moreover, utility and regulator behavior could change, for example, resulting in larger reductions in maintenance expenditures than have been observed historically. To better understand how the impact of future electrification might differ from the past impact of customer base loss, and to inform potential policy options, we next examine data on expenditure patterns at U.S. natural gas utilities and discuss how different categories of expenditure might change with widespread building electrification.

\subsection{Utility Expenditures}

In this section we turn to financial data from an ancillary data source in order to provide additional details about the different categories of utility expenditures. The American Gas Association, a large trade organization, conducts an annual benchmarking survey of around 80 natural gas distribution utilities. The utilities represented are a mix of investor-owned and municipal utilities. They are not a random sample, but together they represent a substantial portion (around 70 percent) of all customers nationwide. Details on this AGA report, and the calculations we make using it, are in the Appendix.

In Table 6, we describe the expenditures of a typical natural gas distribution utility. Perhaps not surprisingly, the single largest expenditure is purchasing natural gas (over $\$ 300$ per residential customer per year). Recall that our previous analysis netted out this expenditure to focus on fixed costs related to pipelines.

The second largest expenditure for a typical utility (around $\$ 170$ per residential cus-

\footnotetext{
${ }^{19}$ Several previous papers document a negative price elasticity of demand for natural gas. Davis and Muehlegger (2010) estimate short-run elasticities of -0.28 and -0.21 for residential and commercial customers, respectively. Hausman and Kellogg (2015) estimate short-run elasticities of -0.11 and -0.09 and long-run elasticities of -0.20 and -0.23 for residential and commercial customers, respectively. Auffhammer and Rubin (2021) estimate a medium-run elasticity of -0.20 . Finally, Davis (2021) shows that natural gas prices also matter for extensive margin decisions, with a $10 \%$ increase in natural gas prices increasing adoption of electric heating by 2 percentage points.
} 
tomer per year) is for past capital expenditures. The largest capital expenditures are main and service pipelines, but examples of smaller categories are compressor station equipment, building structures, tools, and trucks. The capital expenditures category is composed of both annual write-downs of past capital (that is, depreciation) - around $\$ 63$ per residential customer per year - and a payment to investors for their return on past capital expenditures (around $\$ 105$ ). At any given utility, this amount will depend on depreciation to date as well as the rate of return allowed by utility regulators. These first two categories, expenditures for natural gas and capital expenditures, together account for about two-thirds of total utility expenditures.

The remaining one-third consists of operating expenditures and taxes. The next category (\$85 per residential customer per year) is administrative expenses, including salaries to executives, pension payments, etc. Distribution operations and maintenance (averaging around $\$ 66$ per residential customer annually) refers to labor and materials for operating and maintaining the distribution network (pipelines as well as customer meters). Finally, utilities have expenditures related to servicing accounts $(\$ 25$ per residential customer per year), which includes meter reading but also expenses related to nonpayment.

The last column of Table 6 shows our assumptions about how each of these categories of expenditure change in response to customer base loss. First, we assume that 100 percent of expenditures on natural gas are eliminated when a customer exits. The utility no longer needs to procure natural gas on that customer's behalf so these costs are clearly marginal to the customer. Second, we assume that 0 percent of past capital expenditures are eliminated when a customer exits, reflecting the fact that these are a sunk cost that must still be recovered even when a customer exits. ${ }^{20}$

Third, we assume that between 10 percent and 90 percent of operating expenses are eliminated when a customer exits, with the exact percentage varying across categories. We assume that half of administrative expenses are eliminated but half are not. Pensions, for instance, must still be paid when a customer exits. However, expenditures on customer assistance can presumably decrease as there are fewer customers to assist. In contrast, we assume that almost none of the distribution operations and maintenance expenditures are eliminated - since the pipeline network has not changed, the same amount of maintenance must be conducted for safety to not be compromised..$^{21}$ We assume some are eliminated because, for instance, the departing customer's meter may no longer need the same maintenance. We assume that most customer-related account expenditures are eliminated, as

\footnotetext{
${ }^{20}$ While cost disallowances are relatively rare in practice, there is precedent for public utility commissions to disallow cost recovery, as we discuss in the following section.

${ }^{21}$ It is also possible that a struggling utility would cut back on maintenance (Evans and Gilpatric, 2017). We discuss potential policy implications in the Conclusion.
} 


\section{Table 6: Expenditure Categories for U.S. Natural Gas Distribution Utilities}

\begin{tabular}{|c|c|c|c|}
\hline Category & Examples & $\begin{array}{r}\text { Average } \\
\text { dollars } \\
\text { per customer } \\
\text { annually }\end{array}$ & $\begin{array}{r}\text { Assumed } \\
\text { portion } \\
\text { leaving with } \\
\text { the customer }\end{array}$ \\
\hline Gas cost & Cost of purchasing natural gas & $\$ 312$ & 1.0 \\
\hline \multicolumn{4}{|l|}{ Capital-related expenditures: } \\
\hline Depreciation & Annual write-down of past capital expenditures & $\$ 63$ & 0.0 \\
\hline Return on net utility plant & Return for investors on past capital expenditures & $\$ 105$ & 0.0 \\
\hline \multicolumn{4}{|c|}{ Operations-related expenditures: } \\
\hline Administrative & $\begin{array}{l}\text { Admin salaries, outside services, pensions, injuries and } \\
\text { damages, customer assistance, advertising }\end{array}$ & $\$ 85$ & 0.5 \\
\hline $\begin{array}{l}\text { Distribution operations } \\
\& \text { maintenance }\end{array}$ & $\begin{array}{l}\text { Maintenance of distribution mains, service lines, and } \\
\text { meters }\end{array}$ & $\$ 66$ & 0.1 \\
\hline Accounts & Meter reading, customer records, and uncollectibles & $\$ 25$ & 0.9 \\
\hline Taxes & Sales, income, property, etc. & $\$ 47$ & 0.6 \\
\hline Total expenditures & & $\$ 703$ & 0.6 \\
\hline
\end{tabular}

Note: This table was constructed by the authors based on financial data from the American Gas Association's "2016-2018 Performance Benchmarks for Natural Gas Utilities" report EA 2020-03. The last column shows the assumptions we make regarding what portion of the category's expenditures are eliminated when a customer leaves; for instance, a utility no longer needs to purchase any gas for that customer (first row), but must still recover all of its past capital expenditures (second and third rows). Note the "Total expenditures" row at the bottom includes gas costs and is therefore higher than the net revenue plotted in Figure 4. The 0.6 calculations in the "Taxes" and "Total" rows reflect a weighted average of the assumed portion for the individual categories. Details on the AGA report and on the assumed portion column are in the Appendix.

a meter reader is no longer needed for that household. We assume that not all of these expenses are eliminated since, for instance, a utility without internet-connected meters must still send a person down the street to read nearby meters of remaining customers, so the cost of meter reading does not decrease one-for-one in some cases. For taxes, we use the weighted average portion from the other categories.

Based on these assumptions, we plot two additional lines in Figure 4, intended to represent upper and lower bounds. As explained earlier, this figure describes how net revenue per customer would change under increasing levels of customer exit, and the central estimate is based on our empirical estimates in Table 4. We construct the bounds using cost information and baseline assumptions from Table 6. For the upper bound, we use all cost categories, including the two categories of capital costs. For the lower bound, we include all cost categories except for the two categories of capital costs.

The upper and lower bounds can be thought of as the price paths for a representative utility at the beginning and end of the depreciation schedule. Going forward, natural gas 
utilities may choose to cease new capital investments if they expect a high degree of building electrification. Without new capital investments, the capital cost component of bills would decrease until eventually reaching zero as these assets are fully depreciated. Thus we would expect the actual price path to be between these upper and lower bounds, but closer to the lower bound in the long run.

Overall, this bounding exercise yields price paths that are remarkably similar to the path we constructed using our empirical estimates. This similarity provides reassurance that our empirical estimates are broadly representative, even though the utilities that experienced customer losses during our sample period tend to be municipally-owned, smaller, and rural. Probably the most important take-away from the broader analysis is that a considerable portion of capital and operating expenses are not eliminated by customer exit. This is consistent with our empirical analysis of net revenue as well as with these calculations based on financial data, and it implies that under electrification scenarios remaining natural gas customers can expect significantly rising bills.

\subsection{Policy Alternatives}

The main takeaway from our empirical analysis is that as customers exit natural gas service, this increases bills for customers left behind. These bill increases have important implications for equity, and we show that there has tended historically to be a pronounced pattern in which these remaining customers disproportionately come from disadvantaged groups. In this section we discuss alternative options for utility financing that could break this historical pattern, and what these alternatives could mean for efficiency and equity. ${ }^{22}$

\subsubsection{Changing the Composition of Customer Exit}

We first discuss a set of policies that would change the composition of customer exit. For example, one type of policy intervention would be to subsidize building electrification for low-income households or other disadvantaged groups, thereby changing the composition of customer exit (and perhaps accelerating overall electrification). While this approach could improve equity, simply funding low-income electrification projects will still result in higher natural gas bills for remaining users, which may prove burdensome for low and middle income customers who do not enroll in the program. Some of these customers may prefer natural gas over electricity (Davis, 2021); may fail to qualify if they are middle-income (Forrester and Reames, 2020); or may have trouble accessing the program (Fowlie, Greenstone and

\footnotetext{
${ }^{22}$ These alternative policies have been previously discussed in Bilich, Colvin and O'Connor (2019); Greenlining Institute (2019); Gridworks (2019); Mahone et al. (2019); Aas et al. (2020); Larson et al. (2020); Karas et al. (2021); National Academies of Sciences, Engineering, and Medicine (2021); and Williams et al. (2021).
} 
Wolfram, 2015; Raissi and Reames, 2020). In addition, such a policy by itself would not solve the underlying financial difficulties of the natural gas utility.

A related set of policies would target electrification policies geographically. Targeted electrification has been suggested as one way to reduce ongoing operations and maintenance costs; in this scenario, whole areas are electrified so that entire sections of the pipeline network can be shut down. One could imagine targeting based on safety and climate goals, particularly in areas where aging pipelines would otherwise be replaced to prevent methane leaks and pipeline accidents - incurring capital costs that would need to be paid by future customers. Such a targeted electrification policy could lead to a more equitable or a less equitable transition, depending on which areas are targeted. Of course, this policy alone does not solve the problem of how to pay for system-wide legacy costs.

\subsubsection{Changing How Utility Customers Pay}

Another set of policies would change how customers pay for natural gas service. For example, one alternative would be to accelerate the depreciation schedules used by utility commissions in rate-making. Accelerated depreciation allows the utility to recover capital costs more quickly, meaning that these investments remain in the rate base for fewer years. This approach could reduce the degree to which these capital costs are shifted over time onto a smaller set of remaining customers. However, this approach not address the problem of ongoing maintenance costs associated with sparsely used pipelines; as we show above, these are not trivial. Another limitation of accelerated depreciation is that it will, in the short term, raise prices for remaining customers even further.

Other related policies would target more directly the underlying incentive problems. Fundamentally, utility financing relies on a stable or growing customer base to recover past costs; in this way, incentives for customer entry and exit are not correctly aligned. One could imagine pricing schemes that correctly align incentives for customer entry and exit. For instance, customers could pay hook-up fees that cover the future stream of capital and operations and maintenance costs, so that if they later exit, they are not leaving remaining customers on the hook.

This approach has some promise, but also faces challenges. Utilities have generally wanted to grow their customer base to bring in new sources of revenue, and a high connection fee disincentivizes future growth (Sherman and Visscher, 1982). ${ }^{23}$ This kind of policy may also

\footnotetext{
${ }^{23}$ It is worth noting that the discussion around widespread customer loss is relatively new - as recently as 2013, some states were instead investigating policy issues related to natural gas distribution extensions, because of low commodity prices induced by fracking. Costello (2013) discusses rate-setting principles in this setting, for instance "growth should pay for itself by requiring new customers to pay the full costs for extending service to their areas" - but does not consider how this principle might account for the potential
} 
face pushback from ratepayer advocates who value energy access.

A closely related alternative would be to charge exit fees. That is, customers departing the system would be asked to cover a portion of the capital and operations and maintenance costs they leave behind. Our empirical analysis implies that exit fees would need to be large - in excess of $\$ 1000$ per household - if they were to completely cover the present discounted value of legacy costs. Such a solution could be very effective at reducing cost shifts, but is likely to be politically and logistically challenging, and would, of course, be highly unpopular with customers who would correctly claim that they were not warned about such fees when they initially signed up for natural gas service. In addition to these substantial obstacles, exit fees would delay the transition of households away from on-site consumption of fossil fuels.

\subsubsection{Shifting Costs to Utility Owners}

There is also the possibility that utility owners would bear some of these legacy costs. For the hundreds of investor-owned and privately-owned utilities in the United States, legacy costs could be disallowed or partially disallowed by regulators, thereby mitigating additional price increases. Cost disallowances would shift the burden away from ratepayers and toward shareholders and other owners. Municipal utilities are not privately owned, so this alternative does not apply. There is a large literature in law and economics on the question of what costs can be disallowed by regulators versus what costs they must allow utilities to recover. Prominent court cases like Hope Natural Gas Co, Market Street Railway, and Duquesne Light Co have considered this question in a number of different contexts. While Hope offers utilities the right to a fair rate of return, the Market Street decision by the Supreme Court makes clear that this does not protect a utility from market forces that are rendering its service obsolete. See, e.g., Kahn (1997); Graffy and Kihm (2014), and Raskin (2014).

Some of the questions that have arisen in these and related cases are (1) whether the investments were prudent at the time they were made, versus whether the investments continue to be economically viable (i.e. used and useful); (2) whether the utility's very existence is at risk; (3) whether the utility has an obligation to serve remaining customers; and (4) whether the risk faced by the utility arises from market forces or from actions taken by regulators. In some of these cases, commissions have allowed utilities to recover investment costs themselves (i.e. depreciation) but not a rate of return on those investments (Rose, 1996). Any whole or partial disallowances would decrease the value of the utility, leading shareholders to bear some of these legacy costs.

exit of customers in the future. 
It is still too early to say what approach utility commissions will take. From an economic perspective, there are clear efficiency benefits from making sure that shareholders have some "skin in the game." A central tenet of law and economics is that agents should bear the costs of their actions. Utilities are constantly making long-term investments and the threat of disallowances helps encourage utilities to make these decisions efficiently, for example, avoiding expensive pipeline replacement projects in locations undergoing rapid building electrification. On the other hand, it is unrealistic to think that shareholders could be made responsible for the entire legacy gas infrastructure. Disallowing too many of these costs would raise the cost of capital for utilities, making it hard for them to finance basic operations, and potentially leading to bankruptcy.

\subsubsection{Paying For Costs Elsewhere}

In addition, there are policy alternatives that would involve shifting legacy costs out of the natural gas sector altogether. One possibility is that customers of electric utilities could instead cover the transition costs associated with the electrification transition. How this is structured would depend on whether the same utility serves gas and electric customers, and if not, on the way in which each utility is regulated. In the United States there are large numbers of both "single-fuel" (selling only natural gas) and "dual-fuel" utilities (selling both natural gas and electricity) (Knittel, 2003). An interesting question moving forward is whether dual-fuel utilities might begin cross-subsidizing natural gas customers by increased revenue collection from electricity customers. This type of cross-subsidization has not been widely done historically and tends to go against the utility ethos of "cost allocation." In addition, electricity rates already include considerable fixed costs of their own, resulting in a price per unit of electricity that exceeds social marginal cost in most parts of the United States (Borenstein and Bushnell, 2022).

Finally, utility fixed costs could be recovered through the general tax base rather than from utility customers. This could include transfers from federal, state, or local government. Indeed, this is done for other natural monopolies, such as the postal service. This approach has also been proposed for electric utilities facing declining cost recovery because of residential rooftop solar adoption (Borenstein, Fowlie and Sallee, 2021). ${ }^{24}$ A variant on this would use cap and trade or carbon tax revenues, rather than the general tax base. ${ }^{25}$

\footnotetext{
${ }^{24}$ Beecher (2020) also discusses the possibility of funding fixed costs via local property taxes, arguing that it may be less regressive than current pricing structures (although note that local taxes would not decouple cost recovery from migration impacts).

${ }^{25}$ Such a policy has been proposed for low-income energy assistance; see Fowlie, Meredith, "California's Billion Dollar Energy Bill Question" Energy Institute Blog, UC Berkeley, April 5, 2021, https:// energyathaas. wordpress.com/2021/04/05/californias-billion-dollar-energy-bill-question/. A
} 


\subsubsection{Summary}

To summarize, a number of policies have been suggested. Our results can contribute to these discussions in a number of ways. First, by recognizing that the transition difficulties associated with electrification are fundamentally a result of the way that natural monopolies in the U.S. recover their fixed costs, proposals that address the underlying issue can be crafted. Second, we point out that there are multiple issues to be addressed, and as such multiple policies may be needed: capital cost recovery; ongoing maintenance cost recovery for safety and environmental reasons; and equity issues. Fully addressing all of these will likely require a combination of policies. Finally, researchers and policymakers may be able to learn from successful policies used in other domains (natural gas, electricity, water, transportation), since the underlying market structure is similar and the underlying economic issues nearly the same.

\section{Conclusion}

The utility business is often thought of as stable and predictable. But we show that U.S. natural gas utilities have experienced a surprisingly large amount of recent change, with many utilities consistently gaining customers while other utilities consistently lost customers over our sample period, 1997-2019. Our paper leverages these changes to test how utility operations and finances evolve during growth and loss. We show that utilities expand the distribution network during years of customer growth but rarely shrink the network during periods of customer loss. Moreover, we find that utility revenues increase one-for-one during years of growth, but decrease by only half as much during years of loss, implying that remaining customers make up the difference through increased prices.

These dynamics have important implications for a growing set of climate policies aimed at transitioning households and firms away from natural gas toward electricity. We show that during our sample period the utilities experiencing customer losses tended to be in cities with higher poverty rates and a higher percentage of African-American residents. Future energy transitions will not follow the exact same pattern, but our results nonetheless highlight the potential for bill impacts to be distributed across households in ways that exacerbate existing societal inequalities. In addition, we use simulation evidence and ancillary data on typical expenditures for U.S. natural gas utilities to show the large potential magnitude of bill impacts. Based on our empirical estimates, for example, we show that bills can be expected

related policy has also been proposed for a more general reform of electricity sector pricing (Shawhan, 2016). The pros and cons of recovering fixed costs through the general tax base are discussed in Viscusi, Vernon and Harrington (2005) - particularly, political economy questions and incentives to control costs. 
to increase by $\$ 115$ dollars per year in response to 40 percent of residential customers exiting the system. In our calculations, residential bills increase sharply and non-linearly in response to additional customer exit.

These dynamics also have major implications for efficiency. A central theme in energy economics is the importance of pricing energy efficiently (Borenstein and Bushnell, 2022). Putting more fixed costs into retail prices threatens to increase deadweight loss for remaining customers. At the same time, higher retail prices for natural gas will also accelerate the transition away from natural gas, prompting further exits, and thus additional price increases, in the natural gas version of the "utility death spiral." Of course, if the environmental externalities of natural gas are very large, this is a "virtuous cycle" in that it accelerates decarbonization. While these dynamics will not last forever, an energy transition of this magnitude affects a large number of U.S. households and businesses, so it is critical to trace out the implications for both efficiency and equity.

Our findings are also relevant for ongoing policy debates about how to handle aging infrastructure in the natural gas system, which carries safety risks and environmental risks. Several of the states that are leading on building electrification are also states working to ameliorate methane leaks and explosion risks (e.g., California, Massachusetts, and New York). Future work could examine the optimal suite of policies to meet multiple goals, especially in older utility service territories with aging pipelines. Future work could also investigate whether there are perverse incentives for utilities with customer base loss - either to cut back on important maintenance, as in Evans and Gilpatric (2017), or to over-invest in capital-intensive replacement projects to earn a future rate of return (Averch and Johnson, 1962).

Finally, it is worth highlighting that this issue of legacy utility costs is not unique to this particular sector. While our analysis focuses on natural gas distribution utilities, customer exit raises similar challenges for funding inter- and intrastate natural gas pipeline infrastructure. As the amount of gas flowing through these long distance pipelines decreases, the fixed costs associated with these investments are spread over a smaller number of customers. The extent to which this occurs in the future depends not just on what happens with building electrification, but also whether a transition away from natural gas occurs in the industrial and electric power sectors. More generally, our work highlights a broader dynamic which can occur in many sectors with large fixed costs including public transportation, water distribution, mail delivery, and traditional telephone service. 


\section{References}

Aas, Dan, Amber Mahone, Zack Subin, Michael Mac Kinnon, Blake Lane, and Snuller Price. 2020. "The Challenge of Retail Gas in California's Low-Carbon Future: Technology Options, Customer Costs, and Public Health Benefits of Reducing Natural Gas Use." California Energy Commission Report CEC-500-2019-055-F.

Auffhammer, Maximilian, and Edward Rubin. 2021. "Decomposing "the" Elasticity of Demand: Empirical and Policy Insights from 300 Million Natural Gas Bills." Working Paper.

Averch, Harvey, and Leland T. Johnson. 1962. "Behavior of the Firm Under Regulatory Constraint." American Economic Review, 52(5): 1052-1069.

Beauregard, Robert A. 2009. "Urban Population Loss in Historical Perspective: United States, 1820 - 2000." Environment and Planning A, 41: 514-528.

Beecher, Janice A. 2020. "Policy Note: A Universal Equity-Efficiency Model for Pricing Water." Water Economics and Policy, 6.

Beecher, Janice A., G. Richard Dreese, and James R. Landers. 1992. "Viability Policies and Assessment Methods for Small Water Utilities." NRRI 91-1\%.

Beecher, Janice A., Patrick C. Mann, and James R. Landers. 1990. "Cost Allocation and Rate Design for Water Utilities." NRRI 90-17, 791-810.

Bento, Antonio M. 2013. "Equity Impacts of Environmental Policy." Annual Review of Resource Economics, 5: 181-96.

Bilich, Andy, Michael Colvin, and Timothy O’Connor. 2019. "Managing the Transition: Proactive Solutions for Stranded Gas Asset Risk in California." Environmental Defense Fund Report.

Bonbright, James C. 1941. "Major Controversies as to the Criteria of Reasonable Public Utility Rates." American Economic Review Papers and Proceedings, 30(5): 379-389.

Borenstein, Severin, and James B Bushnell. 2022. "Headwinds and Tailwinds: Implications of Inefficient Retail Energy Pricing for Energy Substitution." In Environmental and Energy Policy and the Economy. Vol. 3, 37-70. University of Chicago Press.

Borenstein, Severin, and James Bushnell. 2015. "The U.S. Electricity Industry After 20 Years of Restructuring." Annual Review of Economics, 7(1): 437-463. 
Borenstein, Severin, and Lucas W. Davis. 2012. "The Equity and Efficiency of TwoPart Tariffs in U.S. Natural Gas Markets." The Journal of Law and Economics, 55: 75-128.

Borenstein, Severin, Meredith Fowlie, and James Sallee. 2021. "Designing Electricity Rates for An Equitable Energy Transition." Energy Institute Working Paper 314.

Boustan, Leah Platt. 2010. "Was Postwar Suburbanization "White Flight"? Evidence from the Black Migration." Quarterly Journal of Economics, 417-443.

Burger, Scott P. 2019. "Rate Design for the 21st Century: Improving Economic Efficiency and Distributional Equity in Electricity Rate Design." PhD Thesis, MIT.

Carley, Sanya, and David M. Konisky. 2020. "The Justice and Equity Implications of the Clean Energy Transition." Nature Energy, 5: 569-577.

Costello, Ken. 2013. "Line Extensions for Natural Gas: Regulatory Considerations." NRRI Report 13-01.

Crowder, Kyle, and Scott J. South. 2008. "Spatial Dynamics of White Flight: The Effects of Local and Extralocal Racial Conditions on Neighborhood Out-Migration." American Sociological Review, 73: 792-812.

Davis, Lucas. 2021. "What Matters for Electrification? Evidence from 70 Years of U.S. Home Heating Choices." Energy Institute WP 309.

Davis, Lucas W., and Erich Muehlegger. 2010. "Do Americans Consume Too Little Natural Gas? An Empirical Test of Marginal Cost Pricing." RAND Journal of Economics, $791-810$.

Environmental Protection Agency. 2021. "Inventory of U.S. Greenhouse Gas Emissions and Sinks: 1990-2019."

Evans, Mary F, and Scott M Gilpatric. 2017. "Abatement, Care, and Compliance by Firms in Financial Distress." Environmental and Resource Economics, 66: 765-794.

Faust, Kasey M., Dulcy M. Abraham, and Shawn P. McElmurry. 2016. "Water and Wastewater Infrastructure Management in Shrinking Cities." Public Works Management and Policy, 21(2): 128-156.

Forrester, Sydney P., and Tony G. Reames. 2020. "Understanding the residential energy efficiency financing coverage gap and market potential." Applied Energy, 260. 
Fowlie, Meredith, Michael Greenstone, and Catherine Wolfram. 2015. "Are the Non-monetary Costs of Energy Efficiency Investments Large? Understanding Low TakeUp of a Free Energy Efficiency Program." American Economic Review Papers and Proceedings, 105(5): 201-204.

Fullerton, Don, and Erich Muehlegger. 2019. "Who Bears the Economic Burdens of Environmental Regulations?" Review of Environmental Economics and Policy, 13(1): 6282.

Gabel, David, and Steven Burns. 2012. "The Transition from the Legacy Public Switched Telephone Network to Modern Technologies." NRRI Report 12-12.

Galster, George. 2017. "Why Shrinking Cities Are Not Mirror Images of Growing Cities: A Research Agenda of Six Testable Propositions." Urban Affairs Review, 55(1): 355-372.

Glaeser, Edward L, and Joseph Gyourko. 2005. "Urban Decline and Durable Housing." Journal of Political Economy, 113(2): 345-375.

Gorman, Will, Stephen Jarvis, and Duncan Callaway. 2020. "Should I Stay Or Should I Go? The Importance of Electricity Rate Design for Household Defection from the Power Grid." Applied Energy, 73-109.

Graffy, Elisabeth, and Steven Kihm. 2014. "Does Disruptive Competition mean a Death Spiral for Electric Utilities?" Energy Law Journal, 35: 1.

Greenlining Institute. 2019. "Equitable Building Electrification: A Framework for Powering Resilient Communities." Greenlining Institute Report.

Gridworks. 2019. "California's Gas System in Transition: Equitable, Affordable, Decarbonized and Smaller." Gridworks Report.

Hausman, Catherine. 2019. "Shock Value: Bill Smoothing and Energy Price PassThrough." Journal of Industrial Economics, LXVII(2): 242-278.

Hausman, Catherine, and Lucija Muehlenbachs. 2019. "Price Regulation and Environmental Externalities: Evidence from Methane Leaks." Journal of the Association of Environmental and Resource Economists, 569-577.

Hausman, Catherine, and Ryan Kellogg. 2015. "Welfare and Distributional Implications of Shale Gas." Brookings Papers on Economic Activity, 71-125. 
Holland, Stephen P, Erin T Mansur, Nicholas Z Muller, and Andrew J Yates. 2020. "Decompositions and Policy Consequences of an Extraordinary Decline in Air Pollution from Electricity Generation." American Economic Journal: Economic Policy, 12(4): 244-274.

Johnson, Kenneth M., and Daniel T. Lichter. 2019. "Rural Depopulation: Growth and Decline Processes over the Past Century." Rural Sociology, 84(1): 3-27.

Kahn, Alfred E. 1997. "Competition and Stranded Costs Re-Revisited." Natural Resources Journal, 37(1): 29-42.

Karas, Natalie, Michael Colvin, Ted Kelly, Erin Murphy, and Timothy O'Connor. 2021. "Aligning Gas Regulation and Climate Goals: A Road Map for State Regulators." Environmental Defense Fund.

Knittel, Christopher R. 2003. "Market Structure and the Pricing of Electricity and Natural Gas." Journal of Industrial Economics, LI(2): 167-191.

Laffont, Jean-Jacques, and Jean Tirole. 1990. "Optimal Bypass and Cream Skimming." American Economic Review, 80(5): 1042-1061.

Larson, Eric, Chris Greig, Jesse Jenkins, Erin Mayfield, Andrew Pascale, Chuan Zhang, Joshua Drossman, Robert Williams, Steve Pacala, Robert Socolow, Ejeon Baik, Rich Birdsey, Rick Duke, Ryan Jones, Ben Haley, Emily Leslie, Keith Paustian, and Amy Swan. 2020. "Net-Zero America: Potential Pathways, Infrastructure, and Impacts (Interim Report)." Princeton University Report.

Lyubich, Eva. 2020. "The Race Gap in Residential Energy Expenditures." Energy Institute WP 306.

Mahone, Amber, Charles Li, Zack Subin, Michael Sontag, Gabe Mantegna, Alexis Karolides, Alex german, and Peter Morris. 2019. "Residential Building Electrification in California: Consumer Economics, Greenhouse Gases and Grid Impacts." E3 Report.

Manson, Steven, Jonathan Schroeder, David Van Riper, Tracy Kugler, and Steven Ruggles. 2020. "IPUMS National Historical Geographic Information System: Version 15.0 [dataset]." Accessed: 2021-06-16.

Marks, Levi. 2022. "The Abatement Cost of Methane Emissions from Natural Gas Production." Journal of the Association of Environmental and Resource Economists, 9(2): 165198. 
Mason, Charles F, Lucija A Muehlenbachs, and Sheila M Olmstead. 2015. "The Economics of Shale Gas Development." Annual Review of Resource Economics, 7: 269-89.

McRae, Shaun. 2015. "Infrastructure Quality and the Subsidy Trap." American Economic Review, 105(1): 35-66.

National Academies of Sciences, Engineering, and Medicine. 2021. Accelerating Decarbonization of the U.S. Energy System. Washington, DC: The National Academies Press.

Newell, Richard G, and Daniel Raimi. 2013. "Implications of Shale Gas Development for Climate Change." Environmental Science and Technology, 48: 8360-8368.

Raissi, Shiva, and Tony G. Reames. 2020. 'If we had a little more flexibility.' perceptions of programmatic challenges and opportunities implementing government-funded low-income energy efficiency programs." Energy Policy, 147: 111880.

Raskin, David. 2014. "Getting Distributed Generation Right: A Response to 'Does Distributive Competition Mean a Death Spiral for Electric Utilities?'." Energy Law Journal, 35: 263.

Reames, Tony Gerard. 2016. "Targeting Energy Justice: Exploring Spatial, Racial/Ethnic and Socioeconomic Disparities in Urban Residential Heating Energy Efficiency." Energy Policy, 97: 549-558.

Rose, Kenneth. 1996. "An Economic and Legal Perspective on Electric Utility Transition Costs." National Regulatory Research Institute, Columbus, OH (United States).

Shawhan, Daniel L. 2016. "Optimal Pricing of Electricity in a World with Affordable Distributed Energy." RFF Policy Brief No. 16-0\%.

Sherman, Roger, and Michael Visscher. 1982. "Rate-of-Return Regulation and Twopart Tariffs." The Quarterly Journal of Economics, 97(1): 27-42.

Swain, Marian, Emmett McKinney, and Lawrence Susskind. 2020. "Water Shutoffs in Older American Cities: Causes, Extent, and Remedies." Journal of Planning Education and Research.

Van der Ploeg, Frederick, and Armon Rezai. 2020. "Stranded Assets in the Transition to a Carbon-Free Economy." Annual Review of Resource Economics, 12: 281-98. 
Viscusi, W. Kip, John M. Vernon, and Joseph E. Harrington. 2005. Economics of Regulation and Antitrust. The MIT Press. 4th Edition.

White, Matthew W. 1996. "Power Struggles: Explaining Deregulatory Reforms in Electricity Markets." Brookings Papers on Economic Activity: Microeconomics, 1996: 201-250.

Williams, James H., Ryan A. Jones, Ben Haley, Gabe Kwok, Jeremy Hargreaves, Jamil Farbes, and Margaret S. Torn. 2021. "Carbon-Neutral Pathways for the United States." AGU Advances. 


\section{A1 Online Appendix for "Who Will Pay for Legacy Utility Costs?", Davis and Hausman, Journal of the Association of Environ- mental and Resource Economists}

\section{A1.1 Data Appendix}

\section{A1.1.1 Utility Type}

As we describe in the main text, the EIA data on utility ownership type appear to have some error. For instance, some utilities fail to report their type in some years. Other utilities report different types in different years. For instance, "ABBYVILLE CITY OF" typically reports that it is a municipal utility, but in 2002, 2003, 2007, and 2009, it reports no type; and in 2004 it reports that it is both an investor-owned and a municipal utility.

We first take the modal ownership structure across years for each utility. We then investigate and correct some anomalies, such as designating as municipally-run a few utilities with "City of" in their name - after verifying the ownership structure on the utilities' website. We also verify, where possible, the ownership structure on utility websites for utilities with incomplete reporting. We are unable to identify the ownership structure for a little less than three percent of utilities representing fewer than 0.1 percent of total residential customers. These are generally very small utilities without websites, and we group them in with the municipal utilities category.

We drop all observations from EIA-176 that report no residential volume sold and no residential customers. These tend to be interstate transmission companies, such as the "ALGONQUIN GAS TRANSMISSION COMPANY."

\section{A1.1.2 Citygate Prices and Weather Data}

EIA assembles state-level citygate data from Form EIA-857. We primarily use state-by-year citygate prices as reported by EIA. We also report alternative results using state-by-year citygate prices that we calculate ourselves as a sales-weighted average of state-by-month 
citygate prices from an alternative EIA source.

NOAA does not report cooling degree days and heating degree days for the District of Columbia. We use Maryland weather for the DC utility in our sample. We similarly use the Maryland citygate price, as the EIA does not report a DC-specific citygate price.

\section{A1.1.3 Retail Choice and Bundled Customers}

Most natural gas distribution utilities in the U.S. serve primarily bundled customers, meaning that they provide distribution service (e.g. pipeline operation) and they procure the natural gas on behalf of the customer. In most states, less than ten percent of natural gas customers are retail choice customers, meaning that they buy natural gas from a supplier that is different from the distribution utility that provides distribution services. We exclude utilities for which more than ten percent of residential customers are retail choice because revenues from these customers were not reported until the year 2008.

However, volumes and customer counts are reported for both bundled and retail choice customers for all years. This allows us to impute net revenue for all customers, which we do for utilities with ten percent or less of a customer base that is retail choice. Specifically, we construct two versions of the net revenue variable. In the first, we assume that non-gas costs are the same for bundled and retail choice customers. So, we apply the mark-up from bundled customers to all volumes sold. This allows us to keep all utilities in all years. We limit regressions with this variable to just those utilities for whom a substantial fraction (90 percent) of residential customers are bundled customers. This allows us to keep several large utilities (like DTE in Michigan) with primarily bundled customers. In a second version of the net revenue variable, we construct net revenue using total revenue. For 1997 to 2007, this allows us only to keep utilities with zero retail choice customers; for 2008 to 2019, we are able to keep all utilities. 


\section{A1.1.4 Examining Large Changes in Customer Counts and Other Outliers}

Figure A1 shows examples of how we handle large year-on-year changes in customer counts, which may indicate service territory changes or may indicate measurement error.

Figure A1: Examining Large Changes
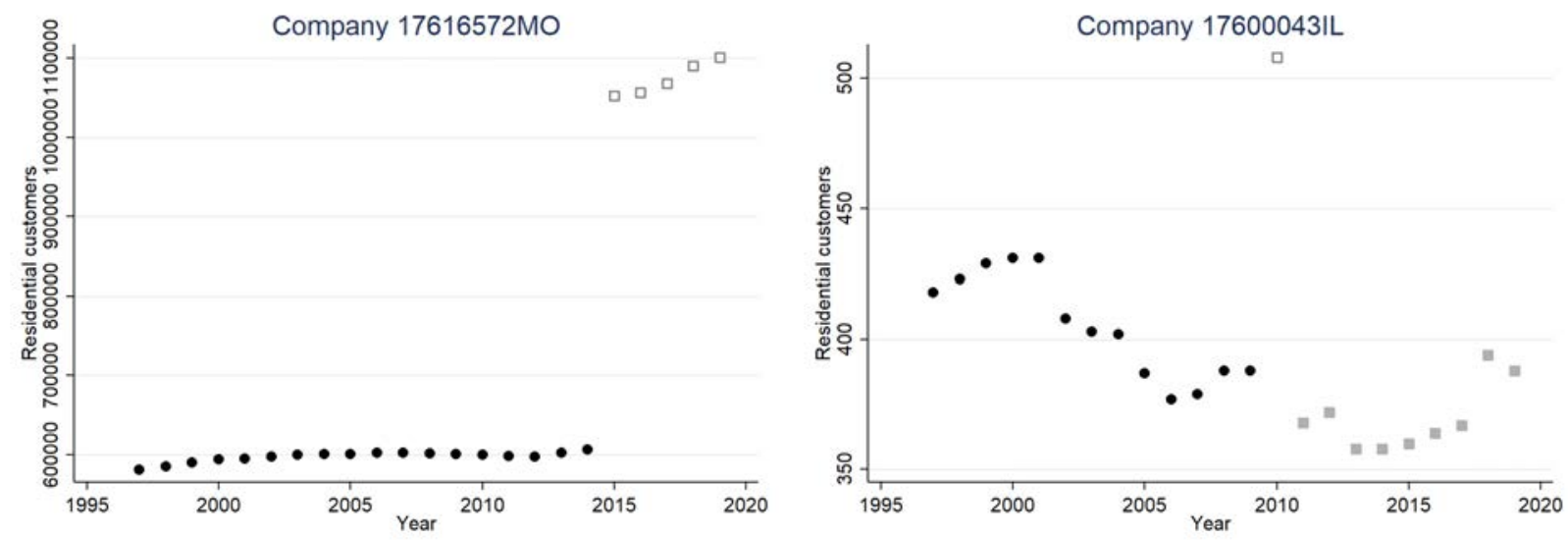

Note: This figure shows examples of utilities with $20 \%$ changes in customer counts from one year to the next. In our specifications estimated in differences, we drop these large changes; this is analogous to assigning separate utility identification numbers whenever a firm's residential customer count changes by more than 20 percent. Sometimes that appears to be because of service territory changes (left panel) and sometimes potentially data entry error (right panel). In the left-hand panel, we drop the 2014 to 2015 change. In the right-hand panel, we drop the 2009 to 2010 change and the 2010 to 2011 change.

In regressions using pipeline miles data, we drop utilities with less than 20 miles of pipeline mains, because growth or loss is likely to measured as very lumpy log changes. ${ }^{26}$ We also drop observations with a change in miles of more than $100 \log$ points. Our net revenue measure is also somewhat subject to outliers; the raw data show both a very large maximum and a negative minimum for the per-customer and per-unit net revenue variables. However, histograms otherwise show a distribution that is fairly close to log-normal. In our main specification, we drop these outliers. ${ }^{27}$

\footnotetext{
${ }^{26}$ For instance, if the utility records in rounded integer values, no change will be recorded for a change from 10.2 to 10.3 miles, but a large log change will be recorded for a change from 10.4 to 10.5 miles. In the raw miles data, utilities vary in the level of precision they report, even across years within the same utility.

${ }^{27}$ We define net revenue outliers in four ways. We drop net revenue observations less than or equal to zero; year-on-year net revenue changes greater than 200 log points; net revenue per customer observations that are more than ten times the median value; and net revenue per unit of gas observations that are more than ten times the median value. In the Appendix, we shows results keeping these observations.
} 


\section{A1.1.5 Merging EIA and PHMSA Data}

To merge the EIA and PHMSA data, we use a fuzzy string match (Stata's reclink command) on utility names and an exact match on the state within which the utility operates. EIA reports the same utility name across all years. The PHMSA dataset lists year-by-year utility names, reflecting both actual name changes and also different abbreviations across years. We merge on the most recent name (2019) for the majority of matches. For firms that fail to match, we evaluate by hand whether an earlier name appears in the PHMSA data that matches to an EIA name. For instance, EIA reports a firm called "NICOR GAS" and PHMSA lists a firm in some years as "NICOR GAS" and in some years as "NORTHERN ILLINOIS GAS CO." We also evaluate by hand failed matches that can be fixed with different abbreviations. For instance, EIA reports a Maryland firm called "BGE" and PHMSA lists a Maryland firm called "BALTIMORE GAS AND ELECTRIC COMPANY."

We are ultimately able to match 83 percent of the EIA observations to PHMSA data (representing 87 percent of residential customers). Of the remaining observations, some represent utility-year combinations for which no data appear in PHMSA. Other failed EIA to PHMSA matches represent utility-year combinations for which there are multiple service territories reported separately in either EIA or PHMSA and no clear matching across the two datasets. Other failed matches represent very small utilities. We also spot-check to verify that matches represent true matches. We verify that all regressions using the full EIA dataset yield similar results when estimated using only the utilities that also appear in PHMSA.

\section{A1.1.6 Population Estimates and Geographic Boundaries of Utilities}

Population estimates by census block group from the decennial census 2000 and five-year data from the American Community Survey 2015-2019 were extracted from IPUMS National Historical Geographic Information System (Manson et al., 2020). These data were then merged with information on the geographic boundaries of about 1,200 U.S. natural gas 
distribution utilities as of 2017 from the Homeland Infrastructure Foundation-Level (HIFLD) Database, http://hifld-dhs-gii.gov/HIFLD. This HIFLD data were constructed by Oak Ridge National Lab using information from EIA-176, corporate websites, maps, American Gas Association data, and other sources. The HIFLD data provide a snapshot of utility service boundaries as of 2017 and we are not aware of any similar national-level data for other years.

\section{A1.1.7 Expenditures Data}

The dollar values per customer in Table 6 are calculated from the American Gas Association's "2016-2018 Performance Benchmarks for Natural Gas Utilities" report EA 2020-03.

The AGA reports dollars per customer of any type rather than dollars per residential customer, so we scale all values by 0.7 - the ratio of the typical residential bill to the typical bill of any customer type in our sample.

We use the median 2018 values from the AGA report's Appendix 3d for depreciation and taxes. Note the depreciation amount is roughly equal to 3.4 percent of the net utility plant per customer reported by AGA; i.e. what would be expected from a 30-year straight-line depreciation schedule. For return on net utility plant, we use "total operating income" in Appendix 3d; note this is roughly comparable to a six percent return on net utility plant, using net utility plant (e.g. minus accumulated depreciation) from Appendix 3b and gas plant per customer from Appendix 3e.

We use the 2018 operations-related expenditures from the AGA report's Appendix 4. For gas cost, we use "total production costs," which are primarily purchased gas expenses. The "Administrative" category includes not only "Administrative Expenses" as defined in the AGA report, but also "Customer Svc. \& Info." and "Sales" [Advertising].

In the AGA report, operations and maintenance expenses for transmission pipelines and underground storage are included in two separate categories and are generally very small (\$4 per customer per year, combining across the two categories). Examples of these ex- 
penditures include maintenance of storage facilities, transmission pipelines, and compressor stations. This low average reflects the fact that at many of the surveyed utilities reported that they do not have any transmission expenditures, whereas some of the larger utilities have transmission expenditures equal to or greater than their distribution-related expenditures. $^{28}$ In Table 6 , we have included these two expenditures types in the "Distribution operations \& maintenance" category. The examples of expenditures within each category are taken from the Uniform System of Accounts.

\section{A1.2 Additional Tables and Figures}

This section contains additional tables and figures referenced in the text, including summary statistics, robustness checks, etc.

Figure A2: Utilities with largest growth and largest loss
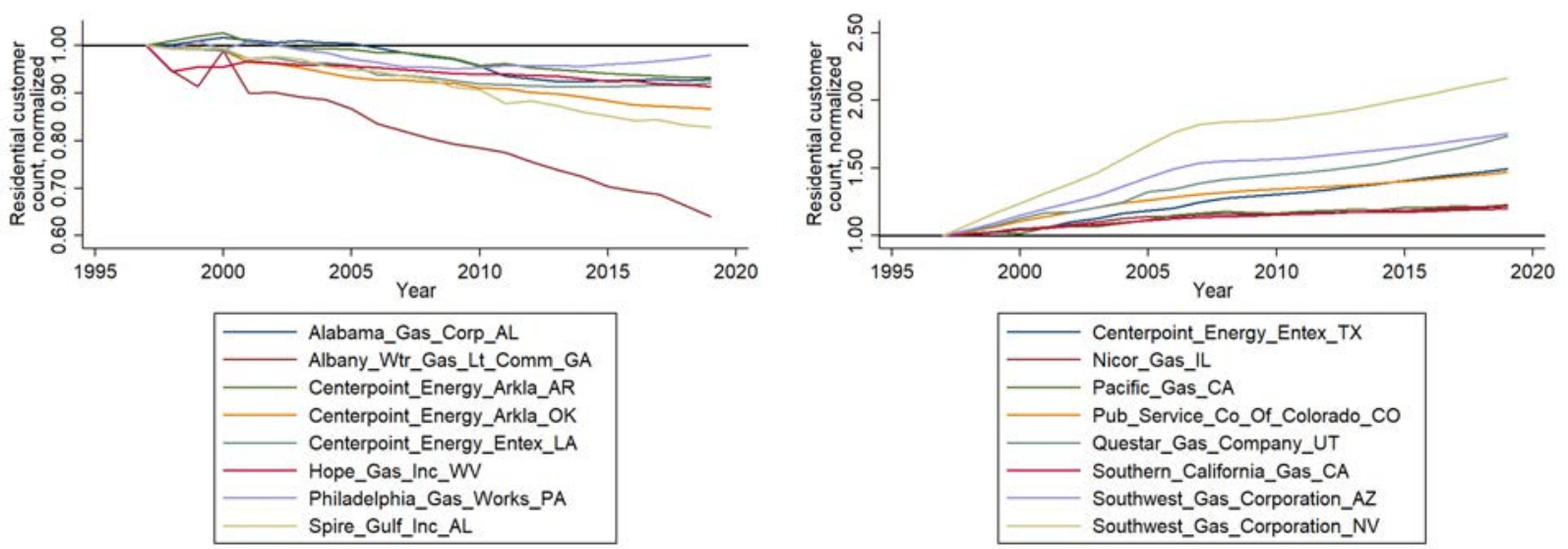

Note: This figure shows residential customer counts for the sixteen utilities displayed in Table 5 in the main text, with each utility's count normalized to one in 1997.

\footnotetext{
${ }^{28}$ The AGA does not report this distribution across utilities, but we examine it with a second dataset of proprietary data from S\&P, which pulls utility financials from state-level regulatory filings.
} 
Figure A3: The Distribution of the Log Change in Miles

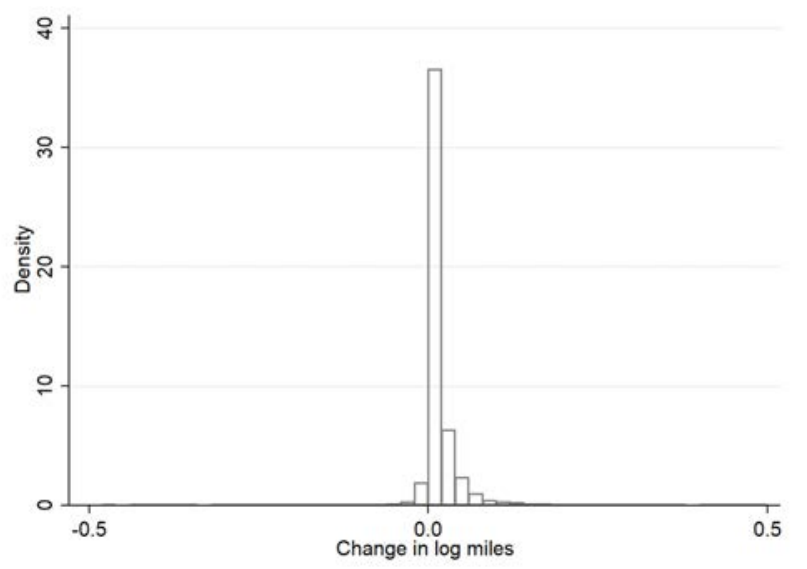

Note: This figure shows a histogram of the log annual change in miles for our main sample.

Figure A4: The Asymmetric Relationship Between Net Revenue and Customers
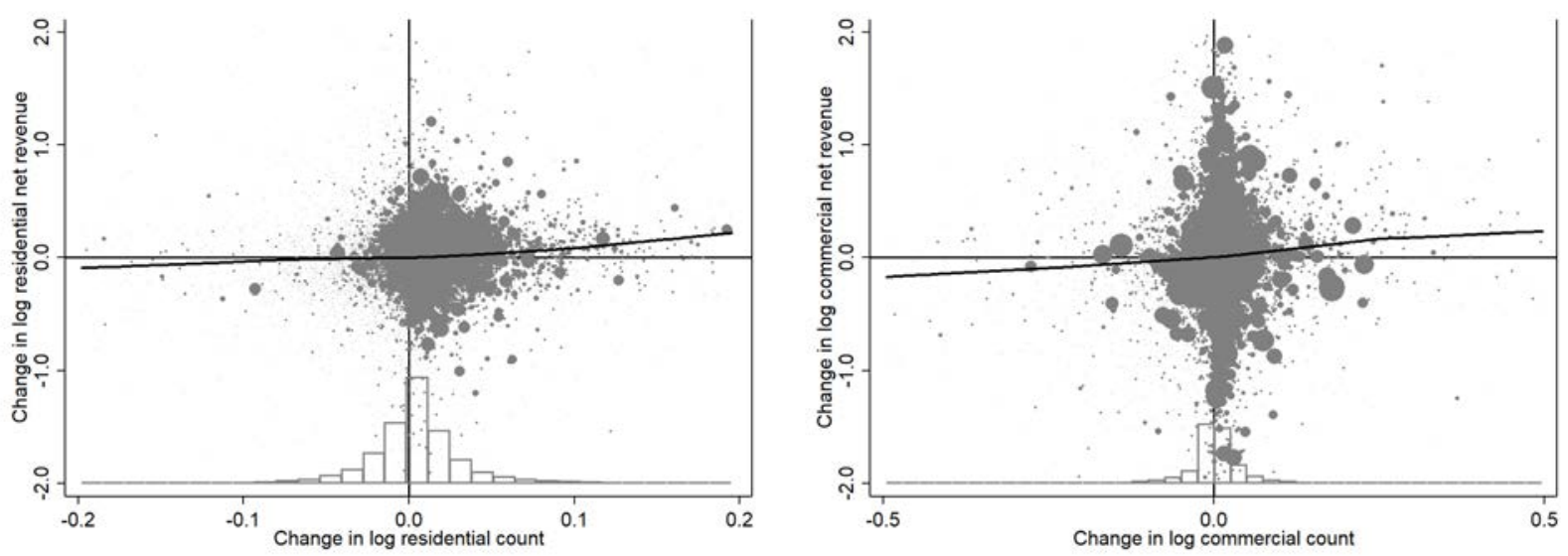

Note: This figure is analogous to Figure 3 in the main text, but for net revenue rather than miles. 
Table A1: Expanded Summary Statistics

\begin{tabular}{|c|c|c|c|c|c|c|}
\hline & $\mathrm{N}$ & Mean & Median & $\mathrm{SD}$ & Min & $\operatorname{Max}$ \\
\hline \multicolumn{7}{|l|}{ Residential: } \\
\hline Customers, '000s & 29,392 & 41.31 & 1.07 & 229.60 & 0.00 & 5607.69 \\
\hline Bundled customers, proportion & 29,392 & 1.00 & 1.00 & 0.01 & 0.90 & 1.00 \\
\hline Dummy, customer base growing & 27,671 & 0.51 & 1.00 & 0.50 & 0.00 & 1.00 \\
\hline Revenue, '000,000s & 28,977 & 27.54 & 0.72 & 129.95 & 0.00 & 3515.88 \\
\hline Net revenue, '000,000s & 28,644 & 17.44 & 0.37 & 86.02 & 0.00 & 2101.42 \\
\hline Per customer, '000s & 28,630 & 0.37 & 0.35 & 0.19 & 0.00 & 3.40 \\
\hline Per mcf & 28,641 & 6.99 & 6.27 & 4.02 & 0.00 & 52.48 \\
\hline \multicolumn{7}{|l|}{ Commercial: } \\
\hline Average price, $\$ / \mathrm{mcf}$ & 28,028 & 12.06 & 11.45 & 4.49 & 0.58 & 181.40 \\
\hline Revenue, '000,000s & 26,215 & 9.38 & 0.38 & 44.23 & 0.00 & 1078.79 \\
\hline Net revenue, '000,000s & 27,138 & 8.29 & 0.20 & 39.31 & 0.00 & 1369.44 \\
\hline Per customer, '000s & 26,859 & 1.70 & 1.27 & 1.57 & 0.00 & 13.00 \\
\hline Per mcf & 27,136 & 5.51 & 4.86 & 3.46 & 0.00 & 42.92 \\
\hline Citygate price, $\$ / \mathrm{mcf}$ & 29,392 & 6.77 & 6.13 & 2.53 & 2.03 & 36.07 \\
\hline Miles of pipeline, '000s & 24,452 & 0.77 & 0.06 & 3.07 & 0.00 & 51.25 \\
\hline$=1$ if investor-owned utility & 29,392 & 0.24 & 0.00 & 0.43 & 0.00 & 1.00 \\
\hline$=1$ if municipal utility & 29,392 & 0.76 & 1.00 & 0.43 & 0.00 & 1.00 \\
\hline
\end{tabular}

Note: This table provides summary statistics for our main estimation sample, an unbalanced panel covering the period 1997-2019, with approximately 1,300 natural gas distribution utilities per year. The sample excludes a small number of utilities for which more than ten percent of customers buy natural gas from a retail choice provider. There are fewer observations for the two "Dummy, customer base growing" variables because they cannot be calculated for the first year a utility appears in the sample. There are fewer net revenue observations for the commercial sector because some utility-year observations have zero commercial customers. There are fewer observations for the "Miles of pipeline" variable because of imperfect matches across data sources. 
Table A2: What Types of Utilities are Growing (Commercial Customer Counts)?

\begin{tabular}{lrr}
\hline \hline & & $\begin{array}{r}\text { Portion } \\
\text { Growing }\end{array}$ \\
\hline All utility-years & & \\
By ownership type: & 24,128 & 0.49 \\
$\quad$ OUs & 6,004 & 0.64 \\
$\quad$ Munis & 18,124 & 0.44 \\
By size in first year: & & \\
1 million or more & 152 & 0.67 \\
100,000 - 1 million & 1,799 & 0.72 \\
10,000 - 100,000 & 2,657 & 0.70 \\
1,000 - 10,000 & 8,593 & 0.54 \\
100-1,000 & 10,443 & 0.35 \\
1-100 & 484 & 0.21 \\
By time period: & 10,687 & 0.50 \\
1997-2007 & 13,441 & 0.48 \\
2008-2019 & & \\
Beographic region: & 495 & 0.76 \\
New England (CT, MA, ME, NH, RI, VT) & 458 & 0.76 \\
Pacific (CA, OR, WA) & 1,208 & 0.66 \\
Mountain (AZ, CO, ID, MT, NM, NV, UT, WY) & 639 & 0.60 \\
Middle Atlantic (NJ, NY, PA) & 3,081 & 0.49 \\
East North Central (IL, IN, MI, OH, WI) & 4,423 & 0.46 \\
West North Central (IA, KS, MN, MO, ND, NE, SD) & 5,430 & 0.48 \\
East South Central (AL, KY, MS, TN) & 3,608 & 0.51 \\
South Atlantic (DC, DE, FL, GA, MD, NC, SC, VA, WV) & 4,786 & 0.37 \\
West South Central (AR, LA, OK, TX) & & \\
\hline & & \\
\hline
\end{tabular}

Note: This table is analogous to Table 2 in the main text, but describing commercial rather than residential customer count changes.

Table A3: Residential Customer Base Growth is Explained by Population Changes

\begin{tabular}{lc}
\hline \hline & Change in Residential Customer Count \\
\hline Household count change in service territory & $0.82^{* * *}$ \\
Constant & $\begin{array}{c}0.01) \\
40.47\end{array}$ \\
& $(805.22)$ \\
\hline Observations & 995 \\
$\mathrm{R}^{2}$ & 0.76 \\
\hline
\end{tabular}

Note: We regress the change in residential customer counts (2000 to 2019), from our utility-level data, on the change in households residing in the service territory (2000 to 2019), using Census Bureau data on household counts and Oak Ridge National Lab data on 2017 service territories. We limit the sample to utilities with at least 90 percent bundled customers in both 2000 and 2019; this drops a small number of utilities that serve retail choice customers. Details on data sources are in the main text. 


\section{Table A4: Pipeline Infrastructure Results, Alternative Specifications}

\begin{tabular}{|c|c|c|c|c|c|c|c|}
\hline & (1) & $(2)$ & $(3)$ & $(4)$ & $(5)$ & (6) & $(7)$ \\
\hline Resi. cust. (log), growing & $\begin{array}{c}0.38^{* * *} \\
(0.04)\end{array}$ & $\begin{array}{c}0.39^{* * * *} \\
(0.04)\end{array}$ & $\begin{array}{c}0.29 * * * \\
(0.04)\end{array}$ & $\begin{array}{c}0.30^{* * * *} \\
(0.03)\end{array}$ & $\begin{array}{c}0.36^{* * *} \\
(0.03)\end{array}$ & $\begin{array}{c}0.45^{* * *} \\
(0.07)\end{array}$ & $\begin{array}{c}0.18^{* * *} \\
(0.05)\end{array}$ \\
\hline Resi. cust. (log), shrinking & $\begin{array}{l}-0.00 \\
(0.04)\end{array}$ & $\begin{array}{l}-0.01 \\
(0.04)\end{array}$ & $\begin{array}{l}-0.01 \\
(0.02)\end{array}$ & $\begin{array}{c}-0.01 \\
(0.03)\end{array}$ & $\begin{array}{l}-0.01 \\
(0.03)\end{array}$ & $\begin{array}{l}-0.00 \\
(0.04)\end{array}$ & $\begin{array}{c}0.01 \\
(0.02)\end{array}$ \\
\hline Comm. cust. (log), growing & $\begin{array}{c}0.03 \\
(0.02)\end{array}$ & $\begin{array}{c}0.03 \\
(0.02)\end{array}$ & $\begin{array}{c}0.01 \\
(0.00)\end{array}$ & $\begin{array}{c}0.02 \\
(0.01)\end{array}$ & $\begin{array}{c}0.02 \\
(0.02)\end{array}$ & $\begin{array}{l}0.06^{*} \\
(0.04)\end{array}$ & $\begin{array}{c}0.01 \\
(0.01)\end{array}$ \\
\hline Comm. cust. (log), shrinking & $\begin{array}{l}-0.01 \\
(0.02)\end{array}$ & $\begin{array}{l}-0.00 \\
(0.02)\end{array}$ & $\begin{array}{c}0.00 \\
(0.00)\end{array}$ & $\begin{array}{c}0.01 \\
(0.01)\end{array}$ & $\begin{array}{c}0.00 \\
(0.01)\end{array}$ & $\begin{array}{l}-0.00 \\
(0.02)\end{array}$ & $\begin{array}{c}0.01 \\
(0.01)\end{array}$ \\
\hline \multirow[t]{2}{*}{$\begin{array}{l}\text { Observations } \\
\mathrm{R}^{2}\end{array}$} & $\begin{array}{c}9,538 \\
0.06\end{array}$ & $\begin{array}{c}9,864 \\
0.06\end{array}$ & $\begin{array}{c}9,651 \\
0.06\end{array}$ & $\begin{array}{c}15,464 \\
0.03\end{array}$ & $\begin{array}{c}12,259 \\
0.05\end{array}$ & $\begin{array}{c}9,544 \\
0.02\end{array}$ & $\begin{array}{c}21,884 \\
0.01\end{array}$ \\
\hline & $(8)$ & (9) & $(10)$ & $(11)$ & $(12)$ & $(13)$ & $(14)$ \\
\hline Resi. cust. (log), growing & $\begin{array}{c}0.40^{* * *} \\
(0.03)\end{array}$ & $\begin{array}{c}0.42^{* * *} \\
(0.07)\end{array}$ & $\begin{array}{c}0.46^{* * *} \\
(0.07)\end{array}$ & $\begin{array}{c}0.38^{* * *} \\
(0.04)\end{array}$ & $\begin{array}{c}0.36^{* * * *} \\
(0.04)\end{array}$ & $\begin{array}{c}0.34^{* * *} \\
(0.04)\end{array}$ & $\begin{array}{c}0.44^{* * *} \\
(0.13)\end{array}$ \\
\hline Resi. cust. (log), shrinking & $\begin{array}{l}-0.04 \\
(0.03)\end{array}$ & $\begin{array}{c}0.24 \\
(0.22)\end{array}$ & $\begin{array}{l}-0.04 \\
(0.06)\end{array}$ & $\begin{array}{c}-0.00 \\
(0.04)\end{array}$ & $\begin{array}{c}0.01 \\
(0.04)\end{array}$ & $\begin{array}{l}-0.02 \\
(0.05)\end{array}$ & $\begin{array}{c}0.05 \\
(0.07)\end{array}$ \\
\hline Comm. cust. (log), growing & $\begin{array}{c}0.01 \\
(0.01)\end{array}$ & $\begin{array}{l}0.05^{*} \\
(0.03)\end{array}$ & $\begin{array}{l}-0.01 \\
(0.03)\end{array}$ & $\begin{array}{c}0.03 \\
(0.02)\end{array}$ & $\begin{array}{c}0.02 \\
(0.02)\end{array}$ & $\begin{array}{c}0.03 \\
(0.02)\end{array}$ & $\begin{array}{c}0.00 \\
(0.01)\end{array}$ \\
\hline Comm. cust. (log), shrinking & $\begin{array}{l}-0.00 \\
(0.02)\end{array}$ & $\begin{array}{c}0.03 \\
(0.03)\end{array}$ & $\begin{array}{c}0.02 \\
(0.04)\end{array}$ & $\begin{array}{l}-0.01 \\
(0.02)\end{array}$ & $\begin{array}{l}-0.00 \\
(0.02)\end{array}$ & $\begin{array}{l}-0.02 \\
(0.02)\end{array}$ & $\begin{array}{c}0.02 \\
(0.01)\end{array}$ \\
\hline Observations & 9,523 & 2,887 & 2,681 & 9,500 & 9,538 & 9,538 & 4,086 \\
\hline $\mathrm{R}^{2}$ & 0.09 & 0.07 & 0.04 & 0.06 & 0.06 & 0.19 & 0.11 \\
\hline
\end{tabular}

Note: This table shows point estimates and standard errors from 14 separate least squares regressions aimed at exploring the robustness of our pipeline infrastructure results to alternative specifications. Column 1 recreates the estimates from the main specification from Table 3. Column 2 includes utilities with customer choice. Column 3 includes large year-on-year log changes that may indicate service territory changes. Column 4 includes one-year regimes. Column 5 includes utilities with small miles counts. Column 6 keeps large left-hand side changes. Column 7 combines the samples from Columns 2-6, keeping all raw data. Column 8 drops even smaller left-hand side changes (50 log points). Column 9 limits to IOUs. Column 10 limits the sample to utilities with at least 10,000 residential customers in every year. Column 11 includes weather and quantity-per-customer controls. Column 12 adds year effects. Column 13 adds fixed effects (specifications are still estimated in differences). Column 14 uses three-year differences rather than one-year differences. 
Table A5: Pipeline Infrastructure, Alternative Specifications

\begin{tabular}{lccccc}
\hline \hline & All & 10+ miles & $20+$ miles & $30+$ miles & $40+$ miles \\
& & & & & \\
\hline \multirow{2}{*}{ Resi. cust. (log), growing } & $0.36^{* * *}$ & $0.37^{* * *}$ & $0.38^{* * *}$ & $0.41^{* * *}$ & $0.42^{* * *}$ \\
& $(0.03)$ & $(0.03)$ & $(0.04)$ & $(0.04)$ & $(0.04)$ \\
Resi. cust. (log), shrinking & -0.01 & -0.02 & -0.00 & -0.02 & -0.04 \\
& $(0.03)$ & $(0.03)$ & $(0.04)$ & $(0.04)$ & $(0.05)$ \\
Comm. cust. (log), growing & 0.02 & 0.02 & 0.03 & 0.01 & 0.00 \\
& $(0.02)$ & $(0.02)$ & $(0.02)$ & $(0.01)$ & $(0.01)$ \\
Comm. cust. (log), shrinking & 0.00 & -0.00 & -0.01 & -0.01 & -0.02 \\
& $(0.01)$ & $(0.02)$ & $(0.02)$ & $(0.02)$ & $(0.03)$ \\
& & & & & \\
\hline \multirow{2}{*}{ Observations } & 12,259 & 11,066 & 9,538 & 8,323 & 7,458 \\
$\mathrm{R}^{2}$ & 0.05 & 0.05 & 0.06 & 0.06 & 0.06 \\
& & & & & \\
\hline
\end{tabular}

Note: This table shows alternative specifications for the asymmetric pipeline results given in Table 3. The first column includes all utilities; subsequent columns drop small utilities with, e.g., less than 10 miles of pipeline.

Table A6: The Impact of Customer Base Changes on Net Revenue

\begin{tabular}{|c|c|c|c|c|}
\hline & Residential & Commercial & Residential & Commercial \\
\hline Customers (log) & $\begin{array}{c}0.65^{* * *} \\
(0.09)\end{array}$ & $\begin{array}{c}0.75^{* * *} \\
(0.06)\end{array}$ & & \\
\hline Customers (log), when growing & & & $\begin{array}{c}1.01^{* * *} \\
(0.13)\end{array}$ & $\begin{array}{c}0.86^{* * *} \\
(0.10)\end{array}$ \\
\hline Customers (log), when shrinking & & & $\begin{array}{c}0.47^{* *} \\
(0.20)\end{array}$ & $\begin{array}{c}0.77^{* * *} \\
(0.11)\end{array}$ \\
\hline D.hdd & $\begin{array}{c}-0.00 * * * \\
(0.00)\end{array}$ & $\begin{array}{c}-0.00 * * * \\
(0.00)\end{array}$ & $\begin{array}{c}-0.00 * * * \\
(0.00)\end{array}$ & $\begin{array}{c}-0.00 * * * \\
(0.00)\end{array}$ \\
\hline D.cdd & $\begin{array}{c}-0.00^{* *} \\
(0.00)\end{array}$ & $\begin{array}{c}-0.00^{*} \\
(0.00)\end{array}$ & $\begin{array}{c}-0.00^{* *} \\
(0.00)\end{array}$ & $\begin{array}{l}-0.00 \\
(0.00)\end{array}$ \\
\hline D.lnresi_qpc1 & $\begin{array}{c}0.37^{* * *} \\
(0.04)\end{array}$ & & $\begin{array}{c}0.37^{* * *} * \\
(0.04)\end{array}$ & \\
\hline D.lncomm_qpc1 & & $\begin{array}{c}0.57^{* * *} \\
(0.03)\end{array}$ & & $\begin{array}{c}0.57^{* * *} \\
(0.03)\end{array}$ \\
\hline resi_dummy_grow_1 & & & $\begin{array}{c}-0.01^{* *} \\
(0.01)\end{array}$ & \\
\hline comm_dummy_grow_1 & & & & $\begin{array}{c}-0.02^{* *} \\
(0.01)\end{array}$ \\
\hline Constant & $\begin{array}{l}0.00^{*} \\
(0.00)\end{array}$ & $\begin{array}{l}0.00^{*} \\
(0.00)\end{array}$ & $\begin{array}{c}0.00 \\
(0.01)\end{array}$ & $\begin{array}{c}0.01^{* *} \\
(0.01)\end{array}$ \\
\hline Observations & 14,437 & 14,017 & 14,437 & 14,017 \\
\hline $\mathrm{R}^{2}$ & 0.02 & 0.08 & 0.02 & 0.08 \\
\hline
\end{tabular}

Note: This table shows the coefficients for all right-hand side variables for the regression results shown in Table 4 in the main text. 
Table A7: Net Revenue from the Residential Sector, Alternative Specifications

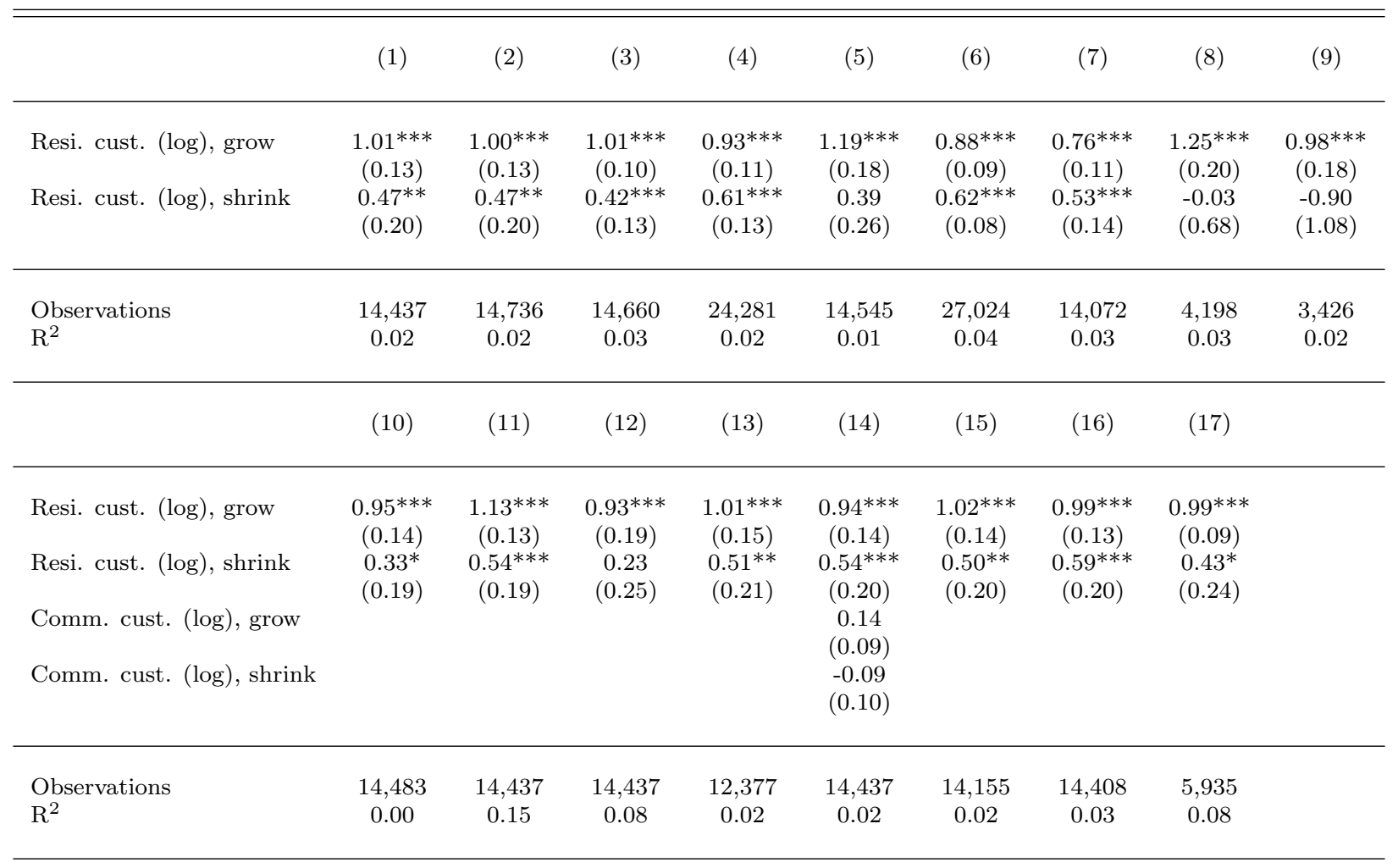

Note: This table shows point estimates and standard errors from 17 separate least squares regressions aimed at exploring the robustness of our net revenue results to alternative specifications. The dependent variable in all regressions is net revenue from the residential sector, in logs. Column 1 recreates the results from Table 4, Column 3. Column 2 includes utilities with customer choice. Column 3 includes large year-on-year log changes that may indicate service territory changes. Column 4 includes one-year regimes. Column 5 keeps large left-hand side changes. Column 6 combines the samples from Columns 2-5, keeping all raw data. Column 7 drops even smaller left-hand side changes (100 log points). Column 8 limits to IOUs. Column 9 limits the sample to utilities with at least 10,000 residential customers in every year. Column 10 drops the weather and quantity-percustomer controls. Column 11 adds year effects. Column 12 adds fixed effects (specifications are still estimated in differences). Column 13 limits the sample to utilities for which we are able to merge PHMSA data. Column 14 includes both residential and commercial variables on the right-hand side. Column 15 uses an alternative net revenue measurement for utilities with retail choice customers. Column 16 uses alternative citygate price data. Column 17 uses three-year differences rather than one-year differences. 
Table A8: Net Revenue from the Commercial Sector, Alternative Specifications

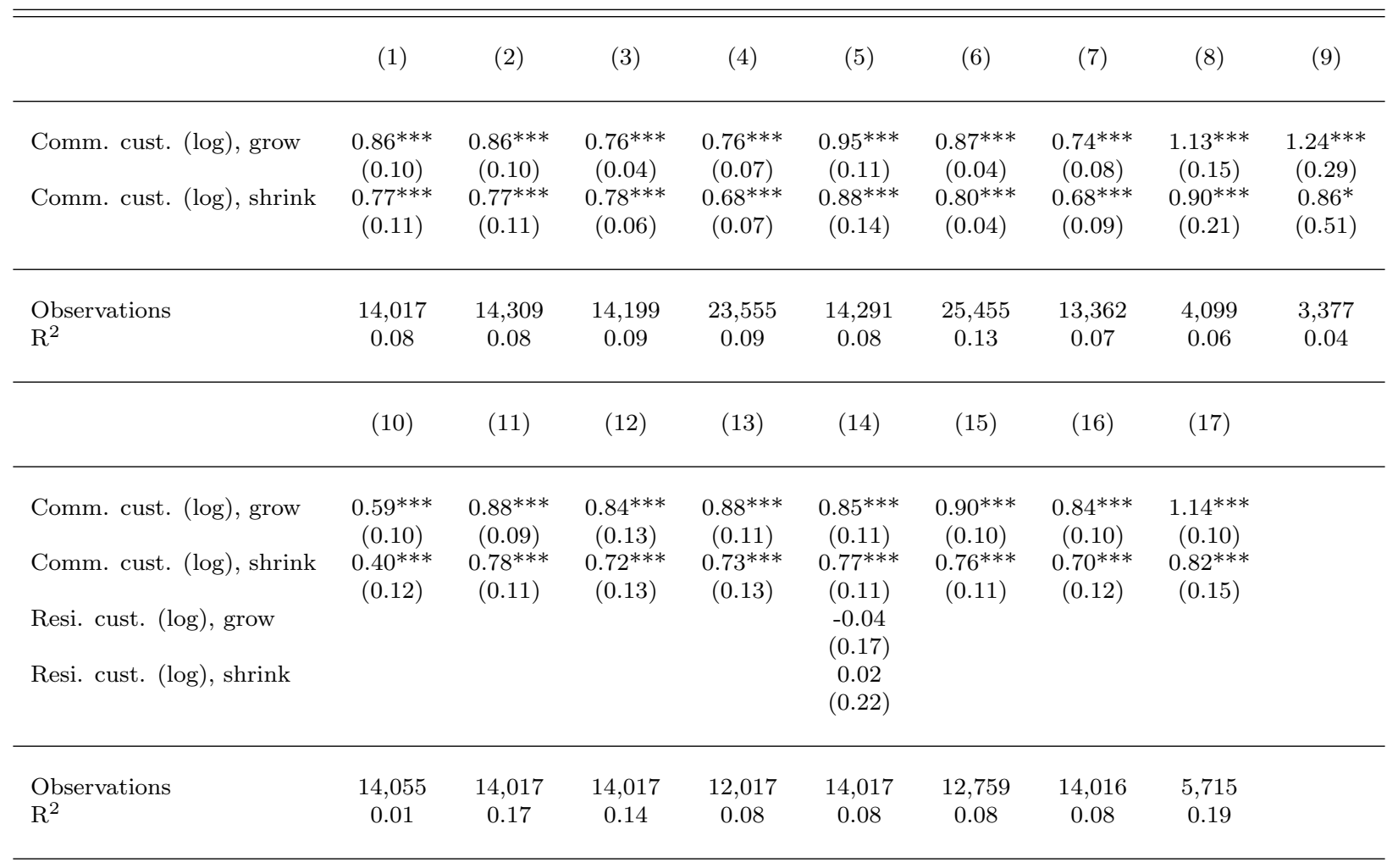

Note: This table shows point estimates and standard errors from 17 separate least squares regressions aimed at exploring the robustness of our net revenue results to alternative specifications. The dependent variable in all regressions is net revenue from the commercial sector, in logs. Column 1 recreates the results from Table 4, Column 4. Column 2 includes utilities with customer choice. Column 3 includes large year-on-year log changes that may indicate service territory changes. Column 4 includes one-year regimes. Column 5 keeps large left-hand side changes. Column 6 combines the samples from Columns 2-5, keeping all raw data. Column 7 drops even smaller left-hand side changes (100 log points). Column 8 limits to IOUs. Column 9 limits the sample to utilities with at least 10,000 residential customers in every year. Column 10 drops the weather and quantity-percustomer controls. Column 11 adds year effects. Column 12 adds fixed effects (specifications are still estimated in differences). Column 13 limits the sample to utilities for which we are able to merge PHMSA data. Column 14 includes both residential and commercial variables on the right-hand side. Column 15 uses an alternative net revenue measurement for utilities with retail choice customers. Column 16 uses alternative citygate price data. Column 17 uses three-year differences rather than one-year differences. 
Table A9: The Impact of Customer Base Changes on Net Revenue Per Customer

\begin{tabular}{lcc}
\hline \hline & Residential & Commercial \\
\hline Customers (log), when growing & 0.01 & -0.14 \\
Customers (log), when shrinking & $\begin{array}{c}(0.13) \\
(0.5 * *\end{array}$ & $\begin{array}{c}-0.10) \\
(0.20)\end{array}$ \\
& & $(0.11)$ \\
\hline Observations & 14,437 & 14,017 \\
$\mathrm{R}^{2}$ & 0.02 & 0.08 \\
\hline
\end{tabular}

Note: This table is analogous to Table 4 in the main text, but the left-hand side is net revenue per customer rather than total net revenue.

Table A10: The Impact of Customer Base Changes on Quantity Per Customer

\begin{tabular}{|c|c|c|}
\hline & Residential & Commercial \\
\hline & $\begin{array}{c}-0.20 * * * \\
(0.05)\end{array}$ & $\begin{array}{c}-0.48^{* * *} \\
(0.07)\end{array}$ \\
\hline Customers (log), when shrinking & $\begin{array}{c}-0.43^{* * *} \\
(0.08)\end{array}$ & $\begin{array}{c}-0.66^{* * * *} \\
(0.07)\end{array}$ \\
\hline Observations & 14,437 & 14,017 \\
\hline $\mathrm{R}^{2}$ & 0.41 & 0.16 \\
\hline
\end{tabular}

Note: This table is analogous to Table 4 in the main text, but the left-hand side is quantity sold per customer rather than total net revenue. 


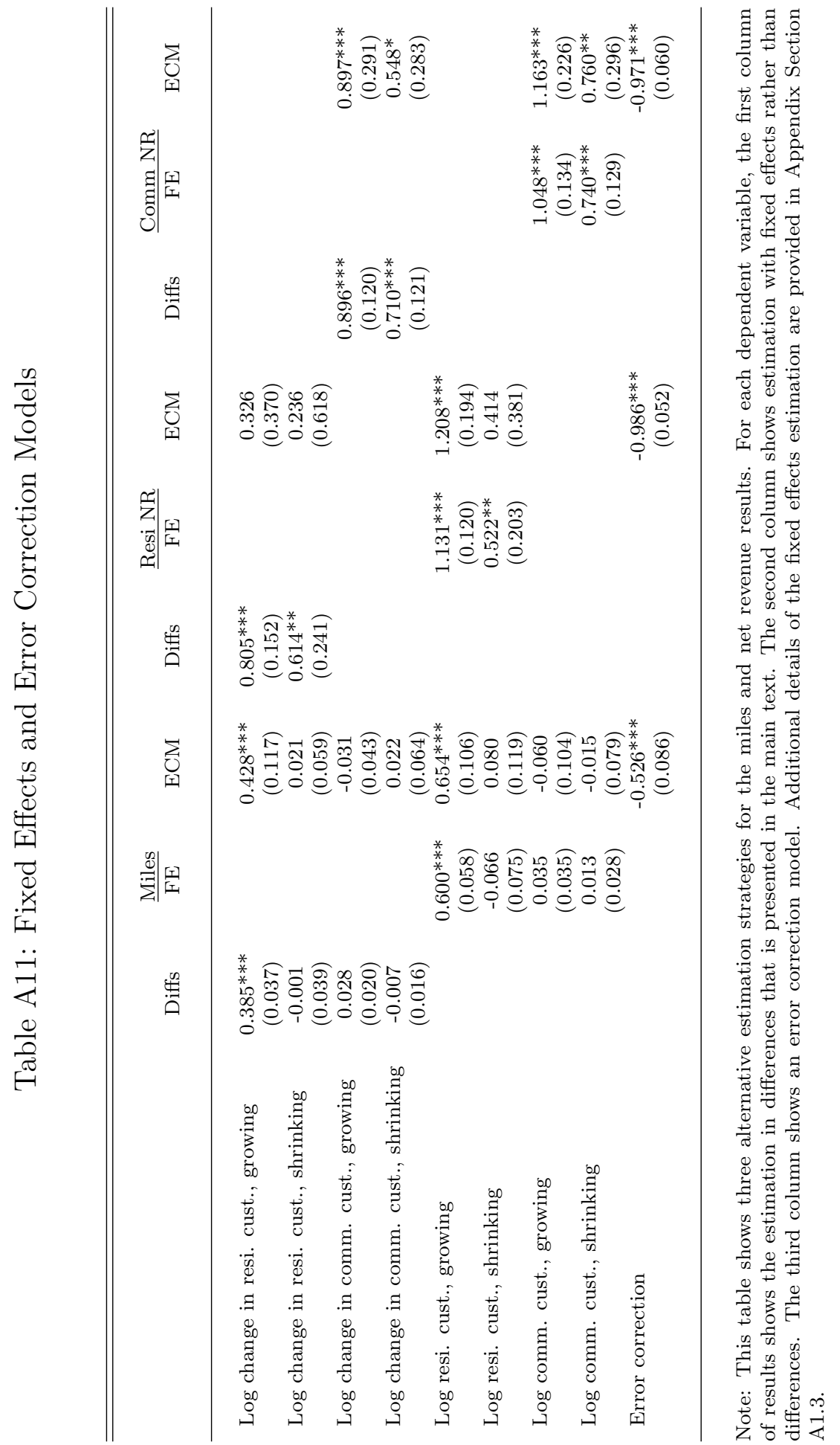




\section{A1.3 Fixed Effects Specifications}

In Table A11, we use a fixed effects estimation strategy and an error correction model, whereas the main specifications are estimated in differences. The regression specifications with fixed effects that account for asymmetry require utility-level effects that change over time. To see this, consider the case of DTE (Detroit Edison, covering Southeast Michigan). DTE has three periods - grow, shrink, grow:

Figure A5: Example Utility With Both Growing and Shrinking Periods

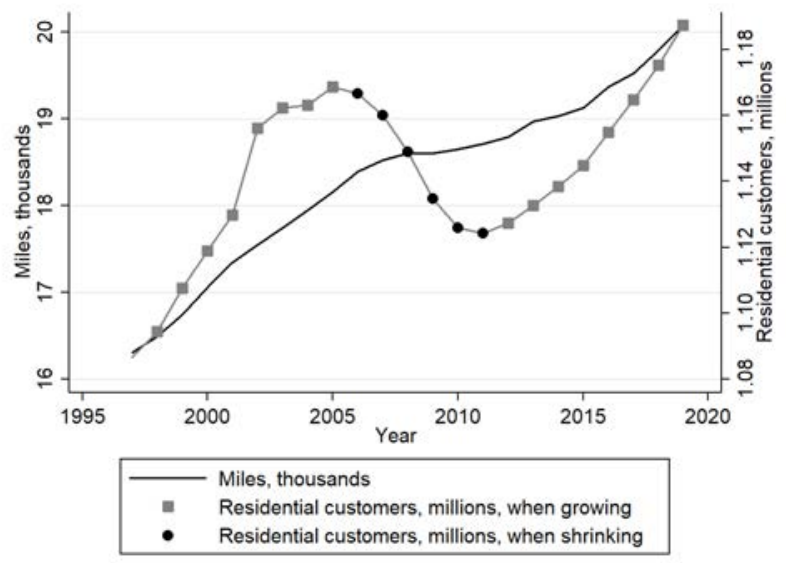

Note: This figure shows miles of pipeline and residential customer counts across time for an example utility in Michigan, DTE. The utility has periods of customer growth (grey squares) and periods of customer base loss (black circles).

The utility has periods of customer growth (grey squares) and periods of customer base loss (black circles). Throughout the sample, miles of pipeline grow, albeit at different rates in different years. In the shrink period, the growth of miles flattens out but does not turn negative. As a result, we expect to see different linear fits between the miles and customer counts variables, depending on whether the utility is growing or shrinking. Pooling across these different time periods yields a poor fit, in particularly failing to capture the flatter (and slightly negative) slope in periods when the utility's customer base is shrinking (Figure A6).

As a first step, one can estimate separate linear fits in the shrinking and growing years. For this particular example, pooling the two growth periods is provides a decent fit (left-hand 
Figure A6: Failing to Account for Asymmetry

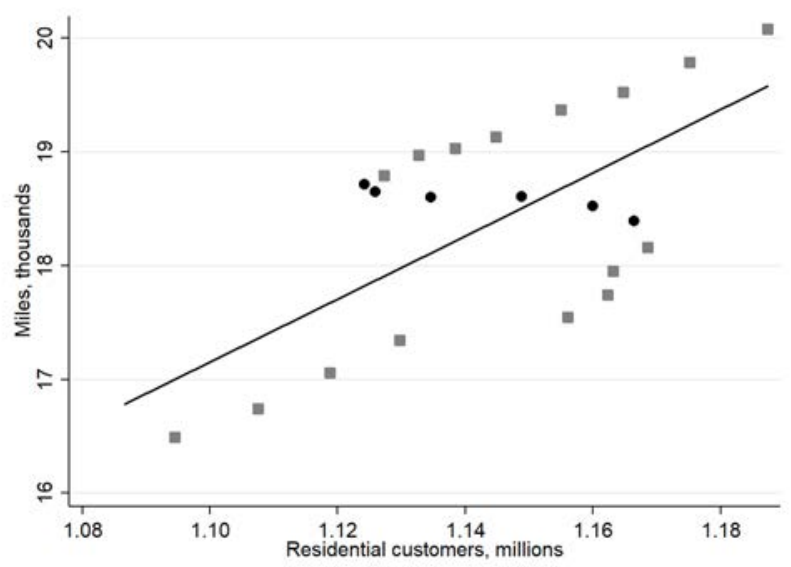

Note: This figure shows miles of pipeline and residential customer counts across time for an example utility in Michigan, DTE. The utility has periods of customer growth (grey squares) and periods of customer base loss (black circles). A linear fit is applied to all observations (black lines), showing a poor fit in the periods of customer loss.

side of Figure A7), but one can see how bias might be introduced in other contexts with multiple periods of growth. To see this more clearly, suppose that we observed only a subset of years of DTE's data, 2002-2015 (right-hand panel of Figure A7). In that case, a linear fit across the two periods of growth yields the wrong slope, since it fails to account for the fact that the two periods have different intercepts.

Figure A7: Failing to Include Different Period-Level Intercepts
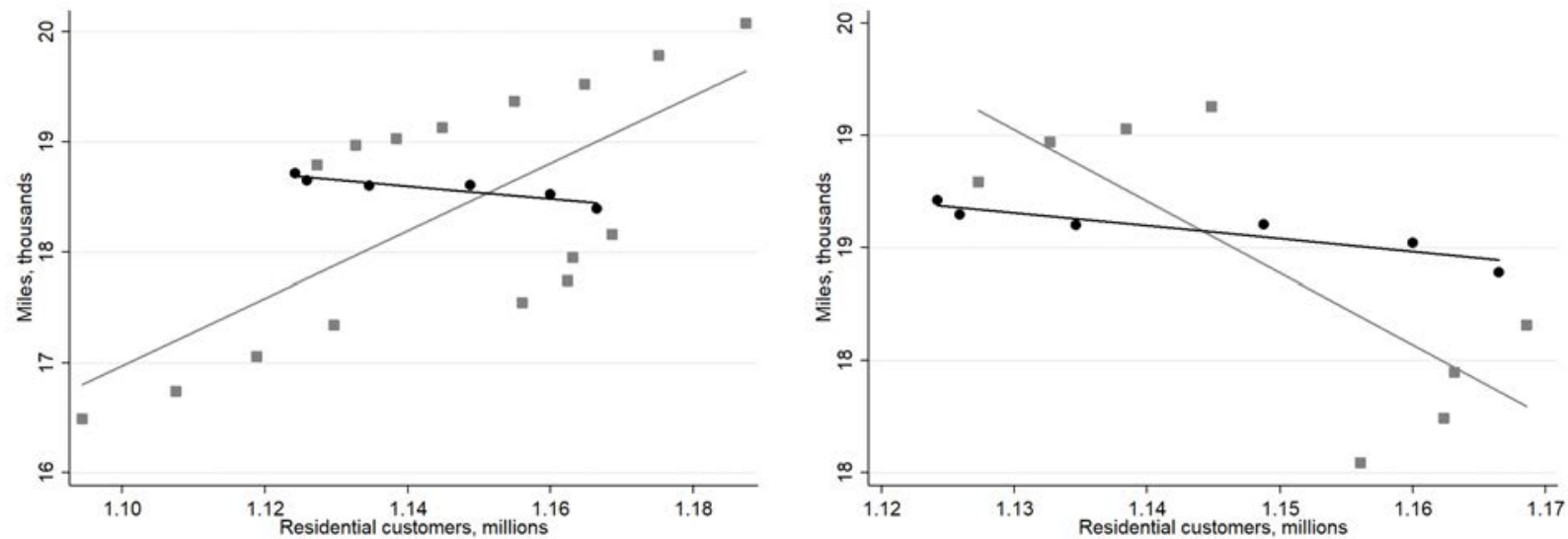

Note: This figure shows miles of pipeline and residential customer counts across time for an example utility in Michigan, DTE. The utility has periods of customer growth (grey squares) and periods of customer base loss (black circles). Separate linear fits are applied to shrinking versus growing periods. In the right-hand panel, suppose we only observed the years 2002-2015. 
To fix this problem, we can apply separate intercepts for each period (Figure A8):

Figure A8: Allowing for Separate Period-Level Intercepts
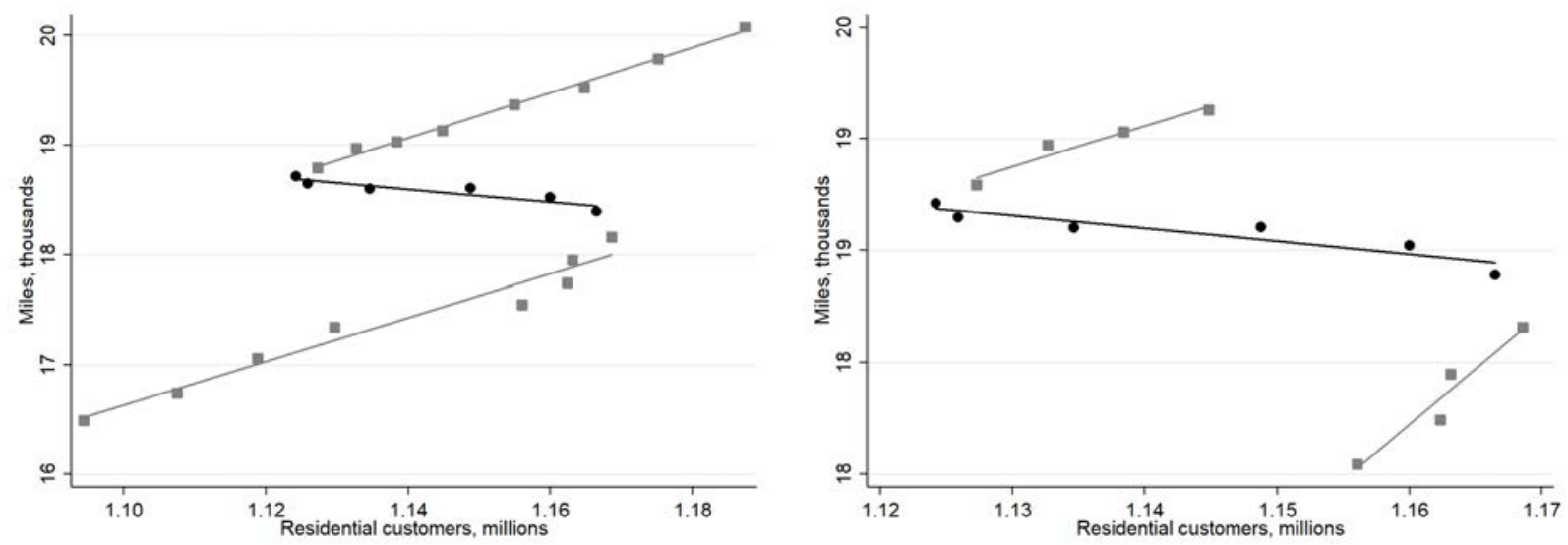

Note: This figure shows miles of pipeline and residential customer counts across time for an example utility in Michigan, DTE. The utility has periods of customer growth (grey squares) and periods of customer base loss (black circles). Separate linear fits are applied to each of three periods. In the right-hand panel, suppose we only observed the years 2002-2015.

When we apply separate linear fits for each of the three periods, we see that the data fit the linear approximation extremely well. Interestingly, the two periods of growth have similar slopes. This suggests that pooling the slope coefficient across these two periods is fine, as long as the intercepts are different, to account for the fact that each regime starts off at a different level of initial pipeline miles.

As such, in our fixed effect regressions, we allow for a different intercept (i.e., fixed effect) for each period of continued growth or continued loss of customers within a utility. In practice, this means that a typical utility will have two or three separate fixed effects (across years). For the purposes of power, we pool the slope coefficients, such that we have just one for all growing periods and just one for all shrinking periods.

\section{References}

Manson, Steven, Jonathan Schroeder, David Van Riper, Tracy Kugler, and Steven Ruggles. 2020. "IPUMS National Historical Geographic Information System: Version 15.0 [dataset]." Accessed: 2021-06-16. 